\title{
StW 573 Australopithecus prometheus: Its Significance for an Australopith Bauplan
}

\author{
Robin Huw Crompton ${ }^{a, b} \quad$ Juliet McClymont ${ }^{a}$ Sarah Elton ${ }^{c}$ Susannah Thorpe ${ }^{d}$ \\ William Sellers ${ }^{\mathrm{e}}$ Jason Heaton ${ }^{\mathrm{f}, \mathrm{g}}$ Travis Rayne Pickering ${ }^{\mathrm{g}} \mathrm{h}^{\mathrm{h}}$ \\ Todd Pataky ${ }^{i}$ Kristian J. Carlson ${ }^{j, g}$ Tea Jashashvilik, m,g Amélie Beaudet ${ }^{\prime}$ \\ Laurent Bruxelles $^{n, o, p} \quad$ Ethan Goh $^{a}$ Kathleen Kuman ${ }^{p}$ Ronald Clarke ${ }^{\mathrm{g}}$

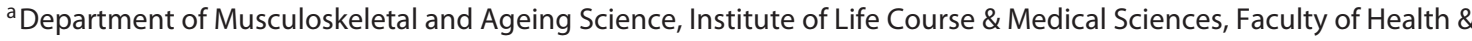 \\ Life Sciences, The W.H. Duncan Building, Liverpool, UK; ${ }^{b}$ School of Archaeology, Classics and Egyptology, University \\ of Liverpool, Liverpool, UK; ' 'Department of Anthropology, Dawson Building, Durham University, Durham, UK;

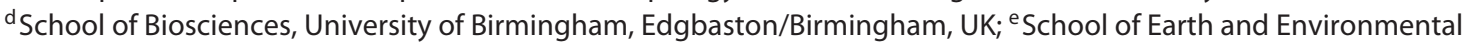 \\ Science, University of Manchester, Manchester, UK; ${ }^{f}$ Department of Biology, Birmingham-Southern College, \\ Birmingham, AL, USA; ${ }^{9}$ Evolutionary Studies Institute, University of the Witwatersrand, Johannesburg, South Africa; \\ ${ }^{h}$ Department of Anthropology, University of Wisconsin Madison, Madison, WI, USA; 'Department of Human Health \\ Sciences, Kyoto University, Kyoto, Japan; 'Department of Integrative Anatomical Sciences, Keck School of Medicine, \\ University of Southern California, Los Angeles, CA, USA; ' Molecular Imaging Center, Department of Radiology, \\ Keck School of Medicine, University of Southern California, Los Angeles, CA, USA; 'Department of Archaeology, \\ University of Cambridge, Cambridge, UK; ${ }^{\mathrm{m}}$ Department of Geology and Paleontology, Georgian National Museum, \\ Tbilisi, Georgia; ' TRACES, UMR 5608 CNRS, Jean Jaurès University, Toulouse, France; ${ }^{\circ}$ French National Institute for

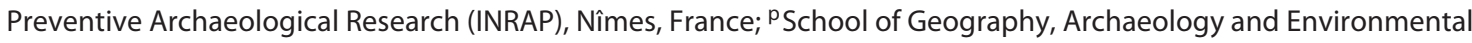 \\ Studies, University of the Witwatersrand, Johannesburg, South Africa
}

\section{Keywords}

Australopithecus · Biomechanics · Bauplan · Ecomorphology · StW 573 ("Little Foot")

\begin{abstract}
The StW 573 skeleton of Australopithecus prometheus from Sterkfontein Member 2 is some $93 \%$ complete and thus by far the most complete member of that genus yet found. Firmly dated at $3.67 \mathrm{Ma}$, it is one of the earliest specimens of its genus. A crucial aspect of interpretation of locomotor behaviour from fossil remains is an understanding of the palaeoenvironment in which the individual lived and the manner in which it would have used it. While the value of this
\end{abstract}

ecomorphological approach is largely accepted, it has not been widely used as a stable framework on which to build evolutionary biomechanical interpretations. Here, we collate the available evidence on StW 573's anatomy in order, as far as currently possible, to reconstruct what might have been this individual's realized and potential niche. We explore the concept of a common Australopithecus "bauplan" by comparing the morphology and ecological context of StW 573 to that of paenocontemporaneous australopiths including Australopithecus anamensis and KSD-VP-1/1 Australopithecus afarensis. Each was probably substantially arboreal and woodland-dwelling, relying substantially on arboreal resources. We use a hypothesis-driven approach, tested by: virtual experiments, in the case of extinct species; karger@karger.com www.karger.com/fpr (c) 2021 S. Karger AG, Base

Karger"

Correspondence to:

Robin Huw Crompton, robinhuwcrompton@gmail.com 
biomechanical analyses of the locomotor behaviour of living great ape species; and analogical experiments with human subjects. From these, we conclude that the habitual locomotor mode of all australopiths was upright bipedalism, whether on the ground or on branches. Some later australopiths such as Australopithecus sediba undoubtedly became more terrestrial, allowing sacrifice of arboreal stability in favour of manual dexterity. Indeed, modern humans retain arboreal climbing skills but have further sacrificed arboreal effectiveness for enhanced ability to sustain striding terrestrial bipedalism over much greater distances. We compare StW 573's locomotor adaptations to those of living great apes and protohominins, and agree with those earlier observers who suggest that the common panin-hominin last common ancestor was postcranially more like Gorilla than Pan.

C 2021 S. Karger AG, Base

\section{Introduction}

The fossil record is nearly always a partial record of the dental and bony morphology of individuals, and occasionally an imprint of their activities that may leave a preservable trace (known as ichnofossils and including footprints). To reconstruct complex behaviour of single individuals on the basis of bony morphology, let alone species-typical behaviour, is extremely challenging. Moreover, physical interaction with the outside world is dominated by the hands and feet. These alone make up half the bones in the whole body, while contributing very little to its total mass or volume. It follows that hand and foot bones have very complex interactions with each other, and, via tendons, receive very complex external forces which constitute the step-by-step, grasp-by-grasp estimates made by the brain's motor control system of required action, based on external feedback from the extremities themselves, and the vestibulocochlear, visual and auditory senses. They must be, to a greater or lesser extent, randomized best guesses based on motor learning. This mechanism is widely known as "degeneracy" [Latash et al., 2002; Whitaker and Bender, 2010; Seifert et al., 2016], where many different structures can serve one function, and which operates down to the level of the gene. Degeneracy in systems such as human hands and feet interacts with ecological dynamics to foster evolvability and robusticity [Whitaker and Bender, 2010; Seifert et al., 2016]. By extension, this applies to the great apes, which, evolving in the mid to late Miocene in a period of intense ecological change, have thus been able to respond to climate instability by plasticity, which is particularly evidenced at the muscle fibre level [Neufuss et al., 2014]. However, this "degeneracy" renders the hands and feet, perhaps counterintuitively, relatively uninformative on locomotor adaptation.

Prior to discovery of StW 573, our most complete evidence of locomotor adaptation of early hominins was the one-third complete AL-288-1 skeleton (Australopithecus afarensis). Otherwise, our best evidence came from partial skeletons covering the spectrum of lesser completeness: lacking gnathocranium (such as Sts 14 and StW 431); substantially partial Australopithecus skeletons (such as KSD-VP-1/1 approx. 3.6 Ma [Haile-Selassie et al., 2010]); juvenile material such as Dikika of approximately 3.3 Ma [Alemseged et al., 2005]; or the much younger and now seemingly highly derived Malapa Australopithecus sediba partial skeletons, $\mathrm{MH}-1$ and $\mathrm{MH}-2$, of approximately $1.977 \mathrm{Ma}$ [Berger et al., 2010; Churchill et al., 2013].

Over two decades, an over $90 \%$ complete skeleton has been excavated from Member 2 at Sterkfontein, South Africa. StW 573, dated firmly at approximately $3.67 \mathrm{Ma}$ [Granger et al., 2015] (see Bruxelles et al. [2019] for stratigraphy and Clarke [2019a] for taphonomy). This skeleton is the first discovered for which limb lengths can be directly measured, not estimated, and is roughly contemporaneous with the Laetoli footprint trail, so will be highly informative on gait of early australopiths such as the trail makers [reviewed in e.g. McClymont and Crompton, 2020]. This specimen, StW 573, is an adult Australopithecus prometheus, most likely female [Clarke, 2019a], and includes a partially deformed cranium, full dentition, hands and a partial left foot, almost complete upper and lower limbs, clavicles, scapulae, pelvis, ribs and vertebrae. MicroCT has revealed details on a well-preserved endocast and internal ear [Beaudet et al., 2019a, b]. Together these provide unique opportunities to advance our understanding of Australopithecus skeletal morphology and function. This skeleton was found in an underground karst cave immediately below the habitat in which it lived. Combining this fact with associated palaeoenvironmental data means that we are uniquely positioned to analyse the ecomorphological niche of this single individual of this species. This may in turn inform us on the overall "bauplan" of australopiths. The foot bones of StW 573 have been reported elsewhere [Clarke and Tobias, 1995; Deloison 2003, 2004], with full descriptions of the hands to be presented by Jashashvili et al. [under review]. Given this, and their degeneracy, hand and foot function is not extensively discussed herein. 
Our interpretations of niche should ideally be made within an ecological formulation that is hypothesis- and experiment-driven. We find this in Wainwright's [1991] "Ecomorphology: Experimental Functional Anatomy for Ecological Problems." It updates Bock and von Wahlert [1965] in its focus on performance, and specifically performance of the individual. This approach is vital because it is the reproductive success of the individual that drives adaptation at population and species levels. Wainwright's experimental approach, which he applied for example to cichlid fishes, obviously cannot be applied directly to extinct animals, but with appropriate circumspection, analogy to experiments on individuals of closely related species, and increasingly now, biomechanical simulation using a skeletal model of the individual under study does provide a way forward to analyse their performance capabilities.

In Wainwright's [1991] formulation, ecomorphology may be examined at three partially overlapping levels. Level a is the realized niche - that behaviour adopted by an individual or population in a given environment at a given time. With reference to locomotor behaviour, this would include knuckle-walking quadrupedalism in open country by Pan troglodytes. The realized niche of extinct species is most obviously reflected in the skeletal elements of individuals, which reflect lifetime responses to imposed load. Level $\mathrm{b}$ is the potential niche - that which could be adopted given a change in environmental circumstances, either in situ through climate change or by movement of the individual to another region. Thus, crudely put, a human might work in flat fields one year, but engage in arboriculture the next: upright terrestrial walking might then be replaced substantially by climbing. Level $\mathrm{c}$ is the fundamental niche. This is the equivalent of potential niche, applied to the performance capabilities of a higher taxon, assessed, for example, by differential statistical characteristics of postcrania compared to other taxa. It is perhaps yet more a theoretical concept than levels $a$ and $b$, but not dissimilar to a bauplan.

Herein, we attempt to use the ecomorphology framework to partially reconstruct the locomotor ecomorphology of StW 573 and elucidate her locomotor capabilities (section 1). (A little of this material was included in a preprint [Crompton et al., 2020].) A full interpretation of her performance capabilities must await publication of current virtual tendon travel simulations given alternative muscle arrangements. We thus present information provided by analogy to experiments on humans and published modelling work. Following Wainwright's [1991] formulation we (section 2 ) review the published paleoen- vironmental data for Sterkfontein Members 2 and 4 [Bruxelles et al., 2019; Clarke, 2019a] that inform on the likely floral and faunal environment and possible dietary habits. In section 3, we present the StW 573 skeleton in a qualitative discussion of long bone joint shape, which is not fully addressed in Heaton et al. [2019] and present limited metrics (3.1), in comparison with data from the literature, to indicate to what extent StW 573 can be regarded as a "typical" australopith. By extension these may help to inform on a likely fundamental niche of Australopithecus. In section 4 , we review the functional morphology of those features (4.1) the pectoral girdle [Carlson et al., 2021] and (4.2) long limb bones [Heaton et al., 2019] that we consider to be most informative of realized niche. We use metrics from these, from the australopith literature and limited original metrics to plot StW 573's position within the australopith range of variation. In section 5 , we discuss this evidence for a common australopith bauplan and conceivable fundamental niche and present our argument for plasticity (5.1) at intraspecific and higher taxonomic levels and discuss the palaeoecology of StW 573 in relation to $A u$. anamensis and Laetoli Au. afarensis (5.2). In section 6, we review the literature on extinct protohominin locomotion, including in particular Orrorin and Ardipithecus ramidus, and relate this to our handassisted bipedality hypothesis for the arboreal origins of bipedality. In section 7, we review relevant biomechanical performance data for extant great apes and experimentation on humans, and finally (in section 8 ) we review the literature for computer simulation experiments that may inform StW 573's likely performance capabilities and those of other contemporaneous and later australopiths.

We emphasize that until the dentition is available for dietary analysis, and virtual models of StW 573 are completed [Crompton et al., in preparation], we must rely primarily on available palaeonvironmental data to reconstruct her likely locomotor ecomorphology. This includes palaeoenvironmental data from Member 4, as we [Clarke and Kuman, 2019] regard StW 431, coming from Member 4, as most likely a male Australopithecus prometheus.

\subsection{Background}

From the 1960s and the discovery of the close genetic relationship of Pan and Homo, the dominant paradigm for the origins of human bipedalism was based on arguments for a terrestrial, "knuckle-walking" ancestry [see especially Washburn, 1967; and reviewed in Richmond et al., 2001]. However, Senut [1982] noted that no hominin olecranon fossa bears the strong lateral crest seen in all quadrupedal monkeys, Pan, Gorilla and Pongo (but curi- 
ously not apparent in Hylobates, perhaps reflecting the requirements of specialized arm-swinging locomotion). Susman [1983] noted that the metacarpophalangeal joint aspect of the metacarpals of AL 288-1, lacks the transverse dorsal ridges and expanded dorsal articular surfaces associated with knuckle-walking in living African apes. Clarke [1998, 2002], later pointed out that the hand morphology and the limb ratios of StW 573 bear no anatomical evidence that it was a knuckle-walker. Nevertheless, Richmond et al. [2001] returned to a knuckle-walking model, although Dainton and Macho [1999] and Dainton [2001] were already questioning whether "knuckle-walking" was ontogenetically and behaviourally a unitary phenomenon in the African apes. Kivell and Schmitt [2009] provided clear evidence that it was not.

In fact, the idea of an arboreal origin for bipedality is far older. Lamarck [1809, p. 170] says:

As a matter of fact, if some race of quadrumanous animals, especially one of the most perfect of them, were to lose, by force of circumstances or some other cause, the habit of climbing trees and grasping the branches with its feet in the same way as with its hands, in order to hold on to them; and if the individuals of this race were forced for a series of generations to use their feet only for walking, and to give up using their hands like feet, there is no doubt, according to the observations detailed in the preceding chapter, that these quadrumanous animals would at length be transformed into bimanous, and that the thumbs on their feet would cease to be separated from the other digits, when they only used their feet for walking.

Darwin [1859] also endorsed an arboreal origin for bipedality, while in 1934, Keith postulated that in the human ancestor legs would have played a "more important part than the arms in orthograde life in the trees" [Keith, 1934, p. 15]. He concludes: "It was on the trees, not on the ground, that man came by the initial stages of his posture and carriage" [Keith, 1934, p. 15]. By 1946, Hooton had dismissed the "knuckle-walking" element of African ape locomotion as most likely a secondary consequence of high upper body mass associated with arboreal climbing.

More recently, Senut in particular has championed an arboreal origin of human erect bipedality, based on morphological data. In 1980 and 1981, she noted that stabilization of the elbow for knuckle-walking was absent in australopiths, while the supracondylar crest of the humerus was strongly marked, suggesting an important element of climbing in their locomotor repertoire. She therefore rejected Pan as a good model for the locomotion of the last common ancestor with humans. Following discovery of Orrorin tugenensis, Senut's group [Pickford et al., 2005; Galik et al., 2004] argued that in addition to in- ternal features, the proximal femur bears features indicating habitual hip extension, such as the groove for obturator externus on the back of the femoral neck [Day, 1969; Lovejoy et al., 2002]. Together with evidence from the distal thumb phalanx for precision gripping [Gommery and Senut, 2005], these features indicated that this species was fully bipedal and yet partially arboreal.

These morphological observations suggesting arboreal bipedality were supported and extended by detailed field observations of orang-utans (Pongo pygmaeus borneanus) [Thorpe et al., 2007] which identified a large component of hand-assisted arboreal bipedality. Orangutans are too distantly related to humans to be very informative on the origins of human bipedality, but Crompton et al. [2010] noted that hand-assisted bipedality is clearly frequently enough used by lowland Western gorillas to have been recorded for wildlife programmes. Quantification of this and other locomotion of gorillas is currently under way in Gabon under the supervision of Thorpe and Sellers. There do not seem to have been reports of it in Pan. Given its frequency in gorillas and orang-utans, Crompton et al. [2010] proposed hand-assisted arboreal bipedality as the likely origin of human bipedalism.

There is no universal agreement as to whether the separation of humans and their kin from other great apes and their kin should be recognized at the family level (Hominidae), subfamily level (Homininae), tribe level (Hominini) or subtribe level (Hominina). The first author (R.H.C.) does not accept a contrast between "apes" and "humans" as endorsed by Andrews [2020]: considering that humans are typical African apes, and despite the general view that humans are most closely related to chimpanzees, this does not imply that the postcrania of the common human/chimpanzee ancestor resembled that of modern chimpanzees, as we shall argue below. The first author adopts separation at the level of the tribe. Thus, for the purposes of this paper, chimpanzees fall into tribe $\mathrm{Pa}$ nini and gorillas into tribe Gorillini; then both, together with tribe Hominini, fall into subfamily Homininae. Orang-utans fall into subfamily Ponginae, and all of these subfamilies fall into family Hominidae.

\section{Palaeoenvironment}

Reconstruction of the ecomorphology of StW 573 is greatly facilitated by the rare circumstances of its burial and fossilization. We know that StW 573 died from a fall into a vertical shaft directly below its native habitat in the Blaaubank river valley [Clarke, 2019a]. The "death trap" 
nature of the deposition of the Sterkfontein Member 2 fauna, of which StW 573 is part, may skew palaeoenvironmental interpretations because primates and felids are overrepresented and time-averaging probably occurred [Pickering et al., 2004]. Nonetheless, the environment around the cave is cautiously reconstructed as rocky hills covered in brush and scrub, and potentially also a valley bottom with riverine forest, swamp and standing water [Pickering et al., 2004]. Although living representatives of all or nearly all of the fossil species found in Member 2 show a strong terrestrial component to their locomotor repertoires, they were probably comfortable exploiting mixed habitats [Elton, 2007], which suggests that the environment was not completely open. The presence of substantial open areas has also been noted at other southern and eastern African Pliocene sites dated to 3-4 Ma, in contrast to some earlier sites that appear more closed [Pickering et al., 2004]. Although there is little evidence that Member 2 was dominated by dense woodland or forest [ibid.], the presence of colobines certainly suggests that the environment was not completely open, as these monkeys are ecologically dependent on trees [Elton et al., 2016]. Member 2 contains Makapania among the rare bovid fossils. Makapania is a takin-like bovid, and takins today are woodland-dwelling. Bruxelles et al. [2019] note that the Member 2 talus sediments contain evidence of well-developed lateritic soils on the surface, which indicates a stable landscape around the cave entrance, and thus established vegetation in the immediate locality, probably including large trees. The younger Member 4 breccia also contains Makapania, as well as large cercopithecoids [Pickering et al., 2004], and there are numerous fossil fragments of forest vines that would have required large trees [Bamford, 1999]. The species of vine identified (Dichapetalum mombuttense) is today known exclusively from central and western African tropical forest. In Member 2, following a dry period when StW 573 was mummified, there was a change to much wetter conditions that resulted in the formation of flowstones and calcified breccias [Clarke, 2019a]. Whether such conditions were episodic or longer-term is unknown, but there is good evidence for moister environments in both Members 2 and 4.

\section{The StW 573 Skeleton}

The above provides information on the palaeoenvironment which StW 573 inhabited, and from which she fell to her death in a solution fissure. We can now attempt, as far as currently possible, to interpret the skeletal anatomy of this specimen. Here, we integrate the functional anatomy of the StW 573 skeleton as interpreted from the primary regional anatomical descriptions published in a special online issue of Journal of Human Evolution guestedited by Stratford and Crompton [2021]. In addition to information therein provided on taphonomy by Clarke [2019a] and stratigraphy by Bruxelles et al. [2019], a detailed inventory of the StW 573 partial skeleton was presented by Clarke [2019a], and a full description of the skull by Clarke and Kuman [2019]. The endocast and inner ear are reported by Beaudet et al. [2019a, b], and the atlas was described in a paper published elsewhere by Beaudet et al. [2020]. The long limb bones have been reported in Heaton et al. [2019] and the pectoral girdle in Carlson et al. [2021]. Jashashvili et al. [under review] will report on hand and wrist morphology. The foot bones were reported earlier, by Clarke and Tobias [1995] and Deloison [2004] and have been extensively discussed more recently by Jashashvili et al. [2020] and Zipfel and Wunderlich [2020].

In summary, StW 573 has: a complete cranium and mandible; many vertebrae and ribs; a partial pelvis with ischiopubic ramus; femora (broken but with overlapping morphology allowing confident length reconstruction); one intact and one slightly damaged but measurable tibia; partial left and right fibulae that overlap sufficiently to be sure of length and morphology; a partial left foot (consisting of calcaneum, talus, navicular, all three cuneiforms, and proximal halves of first and second metatarsals) and a partial lateral cuneiform from the right foot [see Deloison, 2003, 2004]; two scapulae (the right being articulated with the humerus); both claviculae; both humeri (one partially crushed); both radii and ulnae, the left side nearintact and the right side crushed by rock pressure but in articulation with the humerus; and finally one partial and one virtually complete hand (the latter missing only one distal phalanx). The complete skeleton and, in more detail, the limb bones of StW 573 are presented in Figure 1. The pelvis, crushed and deformed on the left side, requires virtual reconstruction before its traits and functional morphology can be fully interpreted with confidence.

Metrics: data from these sources and the literature are the primary source of the Tables and Figures in this contribution, but we (Elton) made supplementary tests for the right clavicle of StW 573. Given the delicate state of the StW 573 fossils, these were taken with digital calipers on a high-quality first-generation epoxy resin cast prepared by Clarke. We estimated stature for StW 573 (see 
Fig. 1. a The long limb bones of StW 573 from Clarke [2019b] (original specimen, reused with permission: license 4942050211741). b The full StW 573 skeleton as of 2019, original specimen (photo courtesy Paul Myburgh).
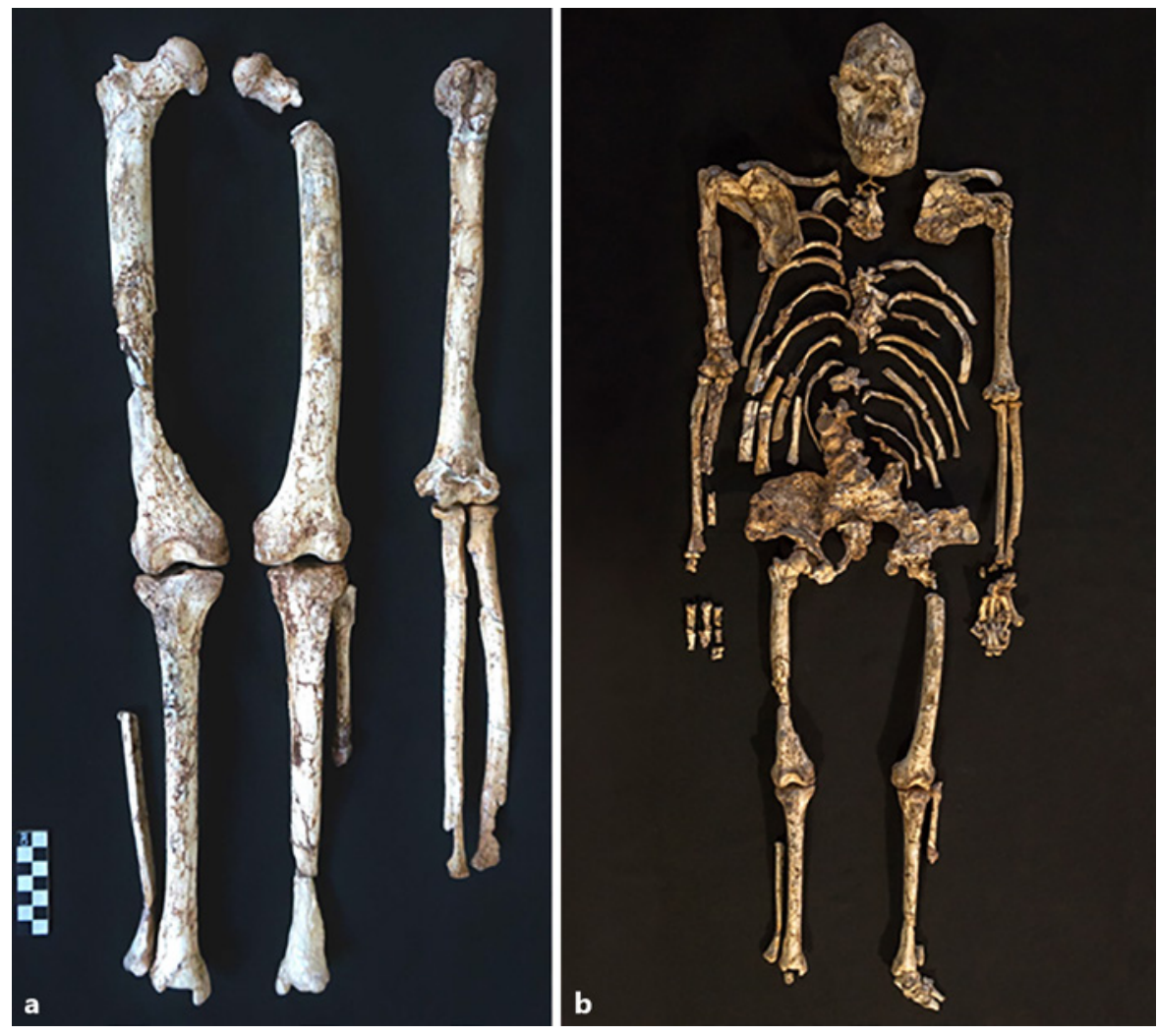

below and Fig. 2) using maximum femoral length (335 $\mathrm{mm}$ [Heaton et al., 2019] and the classical and reduced major axis equations provided in Hens et al. [2000] based on small-stature human ("pygmy") populations. We estimated body mass of StW 573 (see also below and Fig. 2) using the femoral head superoinferior and distal tibia mediolateral equations given in Grabowski et al. [2015]. Femoral head superoinferior width is only an estimate for StW 573, but it was used to calculate body mass, because it was the best performing univariate estimator for other early hominins [Grabowski et al., 2015]. Given that size is itself biologically and evolutionarily meaningful [Dobzhansky, 1973], particularly in the biomechanics of bipedality [Wang and Crompton, 2003], linear dimensions are generally plotted with no adjustment for size, but we include some plots of ratios and indices.

\subsection{Affinities, Proportions, Stature, Body Mass, Age and Sex}

Based on its craniodental morphology, StW 573 is referred to Au. prometheus, discussed at length in Clarke and Kuman [2019]. It is elderly, as judged by cranial sutural fusion, and female, as judged from sciatic notch shape. The taxon $A u$. prometheus, named originally for the parieto-occipital fossil MLD 1, has been shown by Clarke [2019b] to be valid and therefore not a nomen nudum, as incorrectly proposed by Berger and Hawks [2019]. StW 431, found in Sterkfontein's Member 4 [Toussaint et al., 2003], is considered by Clarke and $\mathrm{Ku}$ man [2019] to be a male of the same species.

Although Clarke [1988, 1994, 2013] and Clarke and Kuman [2019] presented cranial and dental data to suggest the existence of a second Australopithecus species in South Africa, there has been ongoing general reticence to accept this interpretation. With reference to specimens other than StW 573, studies on multiple skeletal elements have already pointed to different postcranial morphs at Sterkfontein [Deloison, 2003, 2004; Partridge et al., 2003; Zipfel and Berger, 2009; De Silva et al., 2013; Clarke, 2013; Su and Carlson, 2017; Fornai et al., 2018]. Most recently, Georgiou et al. [2020] have confirmed the existence of different functional morphs at Sterkfontein based on femoral head trabecular architecture and related them to frequency of climbing behaviour.

Moreover, Clarke and Kuman [2019] argue for taxonomic distinction of the morph represented by the partial skeleton of StW 431 and the near-complete StW 573 skeleton, attributed to $A u$. prometheus, versus the form rep- 


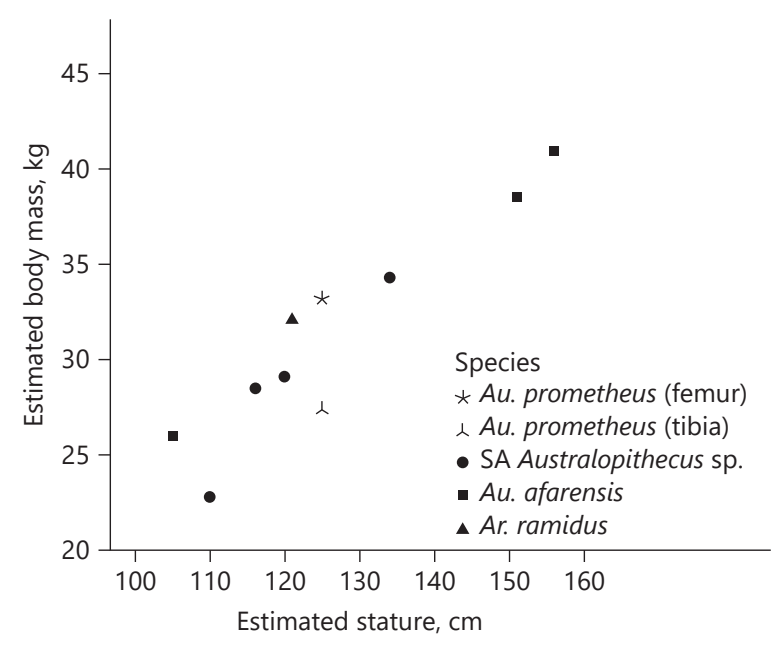

Fig. 2. Estimated stature plotted against estimated body mass for early hominins. Australopithecus prometheus (StW 573) stature estimated from maximum femoral length using the reduced major axis equation from Hens et al. [2000] for small stature populations. Australopithecus prometheus (StW 573) body mass estimated from femoral head superoinferior ("femur") and tibial distal end mediolateral ("tibia") equations given in Grabowski et al. [2015]. Comparable estimated statures and body masses for comparative specimens (South African, SA, Australopithecus sp. [Sts 14, StW 25, StW 443, StW 392], Au. afarensis [AL 288-1, AL 333-3, KSD-VP 1/1], Ar. ramidus [ARA-VP 6/500]) as reported in Will et al. [2017]. StW 573 falls within the range of other early hominins for both estimated stature and body mass. Note that estimates are also provided in Will et al. [2017] for StW 99 but are not included here because the specimen may be Paranthropus [Partridge et al., 2003].

resented by the partial skeleton Sts 14. Macho et al. [2020] reject the association of StW 573 and StW 431. They argue, for example, that parts of the StW 573 iliac margin and iliac spines appear to them to resemble those areas in the chimpanzee in being thinner, thus differing with StW 431 and Sts 14. Although some researchers have noted that it is challenging to interpret the variability present in Australopithecus material from the Plio-Pleistocene of southern Africa [e.g., DeSilva et al., 2013], there is no indication that the different craniodental morphs at Sterkfontein are explained wholly by sexual dimorphism [Clarke, 1994, 2013; Lockwood and Tobias, 2002; Clarke and Kuman, 2019]. Ecologically and taphonomically, the presence of one hominin species at a given location does not rule out the occurrence of a second, just as a number of adaptively similar large-bodied monkeys co-occur, some probably sympatrically, at southern African PlioPleistocene sites [Elton, 2007, 2012]. Sympatry is not un- common in large-bodied extant primates, including gorillas and chimpanzees. Even if hominin species could not live sympatrically, time-averaging in the Sterkfontein deposits could also conceal regional dispersals and local extinctions of multiple hominin species, a phenomenon that has been argued to play a major role in the apparent speciosity of large-bodied carnivorans in the Witwatersrand craton [O'Regan and Reynolds, 2009]. Given the distinguishing features of the StW 573 skull [Clarke and Kuman, 2019], it is thus highly likely that different species are sampled at Sterkfontein within the postcrania as well.

As reported by Heaton et al. [2019], StW 573 is the first Australopithecus for which intermembral limb indices can be stated with confidence. These are outside and above the human range as reported by Schultz [1937] but below the range that he reports for Gorilla at 110-125, and for Pongo at 135-150.9. Heaton et al. [2019] report an intermembral index of 85.5, compared to mean values of 115.8 in Gorilla gorilla, 105.6 in P. troglodytes and 103.4 in Pan paniscus, versus 67.9 for Khoisan, and 68.4 for other Homo sapiens. The classical and reduced major axis equations yielded stature estimates for StW 573 of 123 and $125 \mathrm{~cm}$, respectively. Body mass of StW 573 estimated using the femoral head superoinferior and tibial distal end mediolateral equations yielded values of 33.2 and $27.4 \mathrm{~kg}$, respectively. Although stature estimation for Plio-Pleistocene hominins has limitations, not least because of body proportion differences between them and extant comparative taxa (see Hens et al. [2000] for a review), Figure 2 shows that StW 573 falls within the estimated range of other early hominins. The same is true for body mass, the accurate reconstruction of which is also challenging (see Ruff and Niskanen [2018] for a recent overview). It has been stated that there is high variability in stature and body mass in Pliocene and Early Pleistocene hominins [Will et al., 2017], something that is also evident from the Laetoli footprints [Leakey, 1987; Masao et al., 2016]. However, the extreme rarity of associated cranial and postcranial remains makes estimation of stature and body mass for known Australopithecus species hazardous. Small sample sizes and uncertain taxonomic attributions make both intra- and interspecific comparisons challenging, and the evidence for taxonomically structured variation in body size (stature and mass) among Australopithecus species is equivocal [Will et al., 2017]. The estimated body mass of StW 573 is $27-32 \mathrm{~kg}$, depending on means of calculation. It does little to illuminate taxonomic patterns, falling as it does (Fig. 2) within the (overlapping) ranges of $A u$. afarensis (AL 288-1 being particularly small at $26 \mathrm{~kg}$, the largest being some 


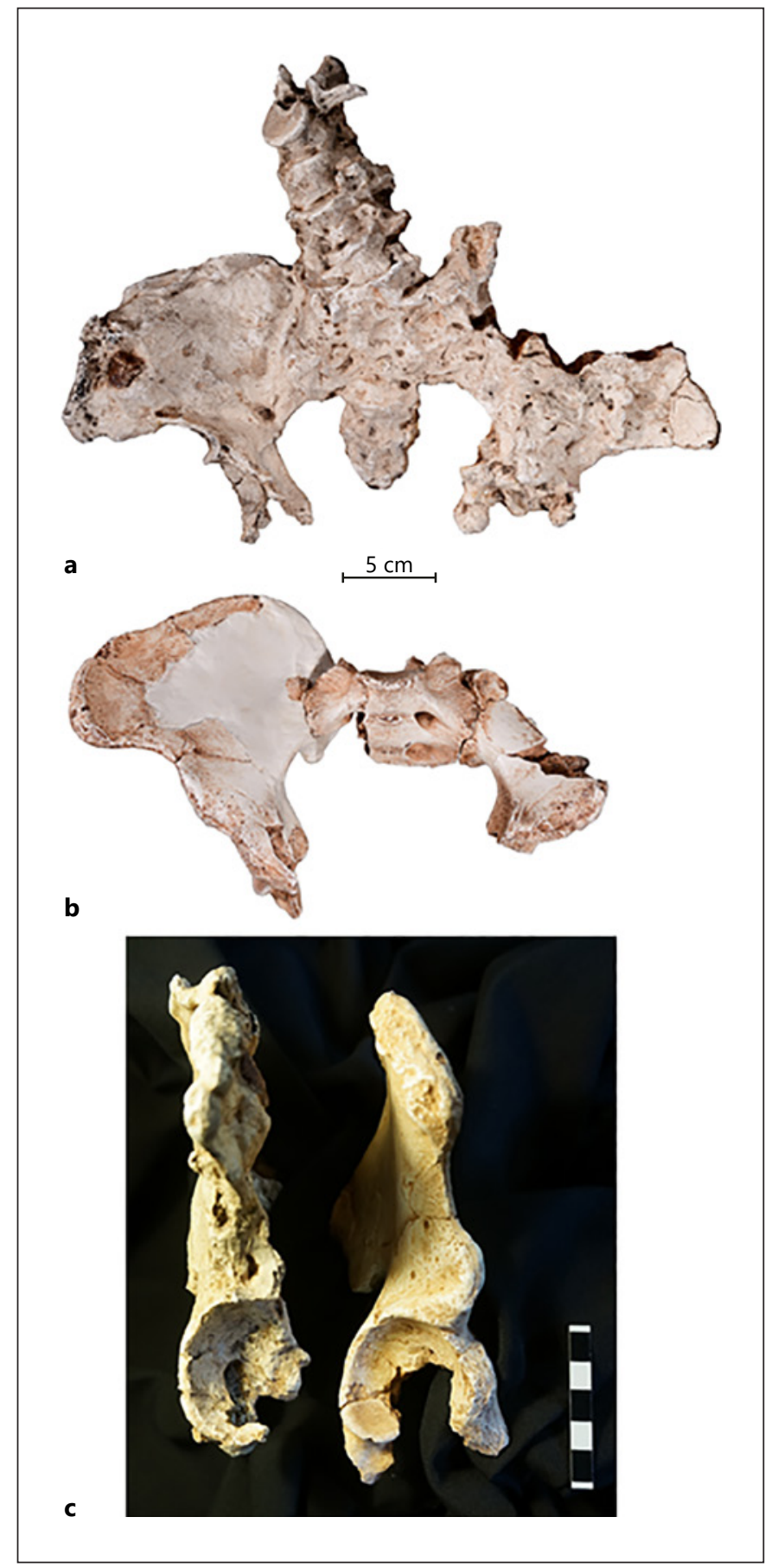

Fig. 3. a Associated pelvic elements and lumbar vertebrae of StW 573. Ischiopubic elements found separately are not included as they are heavily fragmented although in a unit and await publication. Note the apparent lipping of the vertebral bodies. $\mathbf{b}$ Reconstructed pelvis of StW 431. c Lateral views of StW 573 (left) and StW 431 (right) to show similarities in acetabulae. Photos from first-generation casts, courtesy Ronald Clarke.

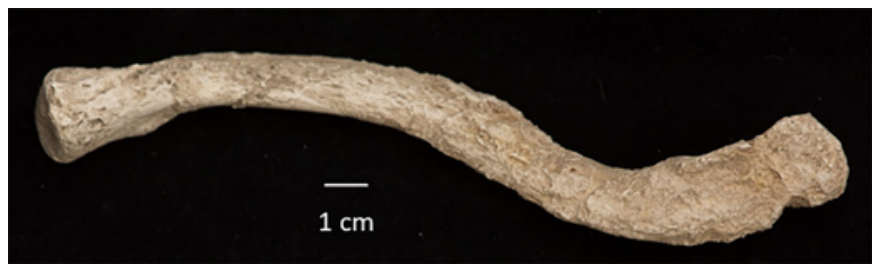

Fig. 4. Superior aspect of the right clavicle, photo by R.H.C. from a first-generation cast. Note the strong sigmoid curvature.

$42 \mathrm{~kg}$ ) and South African Australopithecus as a whole at approximately $23-34 \mathrm{~kg}$.

Lipping of the margins of the lumbar vertebral bodies (Fig. 3) and very heavy toothwear [Clarke and Kuman, 2019], as well as the fusion of cranial sutures noted above [unpubl. data], indicate that StW 573 was an old adult.

As noted above, StW 573 is the only Australopithecus in Member 2 of the Silberberg Grotto [Pickering et al., 2004; Clarke, 2019a]. Perspective is, however, provided by analysis of other South African early hominin fossils. Sts 5, from Sterkfontein Member 4, was diagnosed by Broom et al. [1950] as a mature female, which has now been supported by Villmoare et al. [2013], and hominin adults in the older age classes comprise about $17 \%$ of mandibular and maxillary specimens at Drimolen and $23 \%$ at Swartkrans [Riga et al., 2018]. Thus, even given taphonomic differences between South African cave sites, it is not unusual for older adults to be sampled. Attribution of StW 573 to sex is challenging, given the paucity of early hominin pelves and differences in pelvic form between Australopithecus and modern humans (reviewed in Haeusler and Schmid [1995] and Claxton et al. [2016]). However, based on the method described in Simpson et al. [2008], the greater sciatic notch morphology (Fig. 3) is distinctively female (more details below). Craniodentally, the canines and incisors are small compared to StW 252 (a young $A u$. prometheus specimen), and the base of the cranium is narrow [Clarke and Kuman, 2019]. Endocranial volume is small compared to other, albeit later, Australopithecus [Beaudet et al., 2019a]. These features, alongside general postcranial dimensions [Heaton et al., 2019], also suggest that StW 573 is female.

\section{Functional Morphology of the Fore- and Hindlimb}

\subsection{Functional Morphology of the Forelimb}

Pectoral Girdle. The scapular blade of StW 573 has been subject to reconstruction prior to full interpretation 
Table 1. Clavicle metrics of StW 573 compared to other hominins ${ }^{\mathrm{a}}$ and non-human great apes ${ }^{\mathrm{b}}$

\begin{tabular}{|c|c|c|c|c|}
\hline StW $573^{a, b}$ & 142.9 & 14.3 & 38 & 11.6 \\
\hline KSD-VP-1 & $\sim 156$ & - & 46 & - \\
\hline \multirow[t]{2}{*}{$\mathrm{MH} 2$} & $\sim 108$ & - & 27 & - \\
\hline & $\sim 131$ & - & $\begin{array}{l}\text { Mean } 35 \text { (sample also includes } \mathrm{OH}-48 \text {, } \\
\text { ATD 6-50 and D-41610) }\end{array}$ & - \\
\hline Modern humans ${ }^{b, c}$ & $148.7 \pm 11.3$ & - & Mean $39.2(N=25)$ & - \\
\hline$P_{a n}^{b, c}$ (species unknown) & Mean $117(N=9)$ & - & Mean $35.8(N=25)$ & - \\
\hline Gorilla gorilla ${ }^{\mathrm{b}, \mathrm{c}}$ & Mean $151(N=15)$ & - & Mean $43.2(N=25)$ (species unknown) & - \\
\hline
\end{tabular}

a StW 573 from Heaton et al. [2019] and Carlson et al. [2021]. KSD VP-1 from Haile-Selassie et al. [2010]. MH2 and modern human data from Churchill et al. [2013]. KNM-WT 15000 from Walker and Leakey [1993]. AL 438-1 and AL 333x-6/9 from Drapeau et al. [2005]. ${ }^{\text {b Non- }}$ human great apes, data from Schultz [1930]. ' Churchill et al. [2013] for midshaft circumference.

[Carlson et al., 2021]. It features a large supraspinous fos$\mathrm{sa}$, indicating power in early-stage abduction of the glenohumeral joint, and strong medial buttressing, both recalling the scapulae of non-human great apes. However, the complete right clavicle (Fig. 4), described and figured more fully in Carlson et al. [2021], is broadly humanlike in form, with a strong sigmoid shape in superior view, although the superior and inferior curvatures resemble those of Pan and Gorilla more than those of Homo when viewed from a parasagittal perspective.

The claviculohumeral ratio $(100 \times$ clavicle length/ maximum humerus length) of StW 573 is 49 , within the range of orang-utans [Larson, 2007], modern humans, early modern Homo and Neandertals, but above the ratios of the Dmanisi sample at approximately 44-47, KNMWT 15000 at approximately 41 (see Churchill et al. [2013] for comment on preservation) and $\mathrm{MH} 2$ at 40 [Churchill et al., 2013; Roach and Richmond, 2015]. If shoulder position can be inferred from claviculohumeral ratio [see Roach and Richmond, 2015, for a critique), the relatively long StW 573 clavicle suggests that it was not anteriorly positioned (as has been argued for KNM-WT 15000 [Larson, 2007]), and instead it may be positioned more laterally like that of modern humans, but somewhat more elevated distally than in the latter. Here, the more Pan- and Gorilla-like superior and inferior curvatures need to be borne in mind. However, craniad elevation of the distal clavicle is nothing like that reported for $A u$. sediba, the clavicular form of which has been regarded as indicating a shoulder position considerably higher than that seen in modern humans [Churchill et al., 2013; and see Melillo et al., 2019]. Rein et al. [2017] interpret this degree of elevation as indicating a secondarily derived suspensory locomotion. However, this need not be the case: it might indicate a ground-based adaptation for feeding on bushes, as proposed (for the origins of bipedalism) by Hunt [1994].

A somewhat distally elevated posture of the clavicle in StW 573 is indicated by a rather more cranially oriented glenoid fossa than seen in humans. The supraspinous fossa is large and non-human ape-like, and the axillary side of the scapula is reinforced by a stout ventral bar, as in living non-human apes. The middle third of the StW 573 clavicle is craniocaudally flat with no evidence of inferomedial inflection. Its dimensions are summarized and compared to other relevant taxa in Table 1.

In the scapula, the StW 573 spine was most similar to that of P. pygmaeus in axillary border/spine angle, and slightly more similar to P. pygmaeus than to G. gorilla in medial border/spine angle [Carlson et al., 2021]. An 18 -variable canonical variates analysis of the scapula by Carlson et al. [2021] plots StW 573 on the edge of the G. gorilla cluster (but near a $P$. troglodytes individual at the extreme of the Pan cluster), and further from all other ex- 


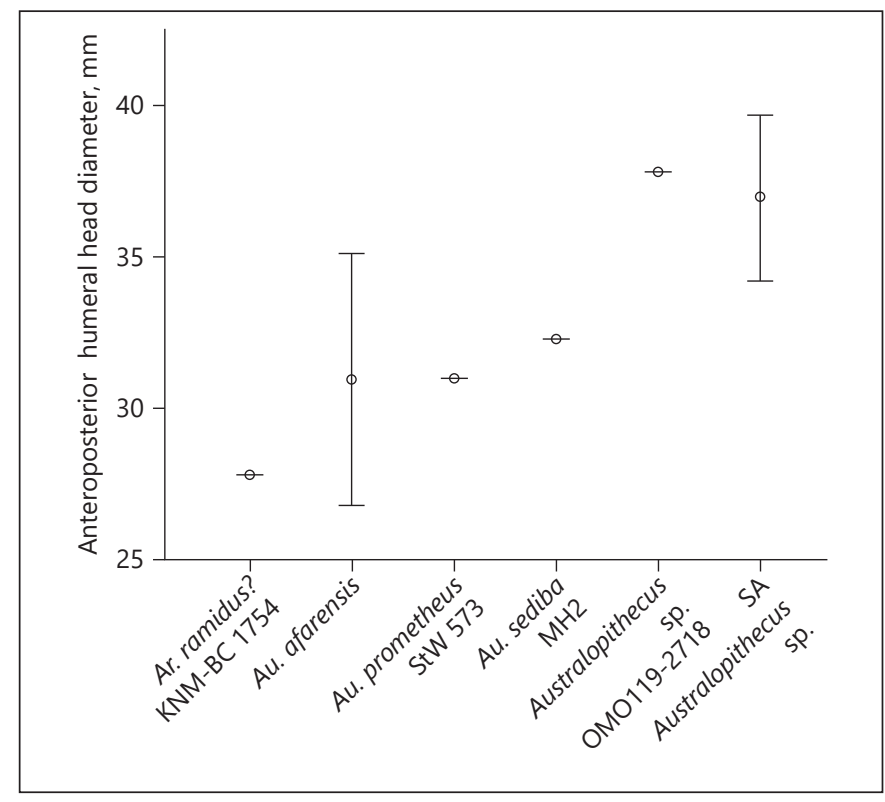

Fig. 5. Anteroposterior humeral head diameters in early hominins. StW 573 falls within the range of other early hominins. Australopithecus afarensis comprises AL 288-1, AL 333-107, and southern African (SA) Australopithecus sp. comprises Sts 7 and Sts 328. Circles represent means and bars maximum and minimum values. Data from Johanson et al. [1982], McHenry [1992], Haile-Selassie et al. [2010], Churchill et al. [2013] and Heaton et al. [2019].

tant taxa. StW 573, DIK-1-1 (R), DIK-1-1 (L) and MH 2 fell close to the means of CV 1 and CV 2, and outside clusters of extant taxa, except that StW 573 fell within the variation of extant gorillas. In an 11-variable canonical variates analysis, StW 573 and MH 2 fell near one another in the area of overlap between G. gorilla and P. pygmaeus. As in the 18-variable canonical variates analysis, StW 573 again fell closer to G. gorilla than other taxa except for MH. Thus, overall, Carlson et al. [2021] found that StW 573 probably agreed with non-human African apes in scapular form to a greater degree than other Australopithecus scapulae (KSD-VP-1/1, MH 2, and both DIK-1-1 scapulae). They conclude that a high glenohumeral joint, a dorsally positioned scapula and relatively more non-human ape-like cranial orientation of the glenoid fossa may have offered selected advantages in below-branch arboreal positional behaviours. However, when synchronous lower limb action is taken into consideration, these would support hand-assisted bipedalism [Thorpe et al., 2007].

Humerus. The left proximal humerus of StW 573 is distorted although the head remains largely complete [Heaton et al., 2019]. Anteroposterior humeral head diameter is estimated as $31 \mathrm{~mm}$, within the range of other early

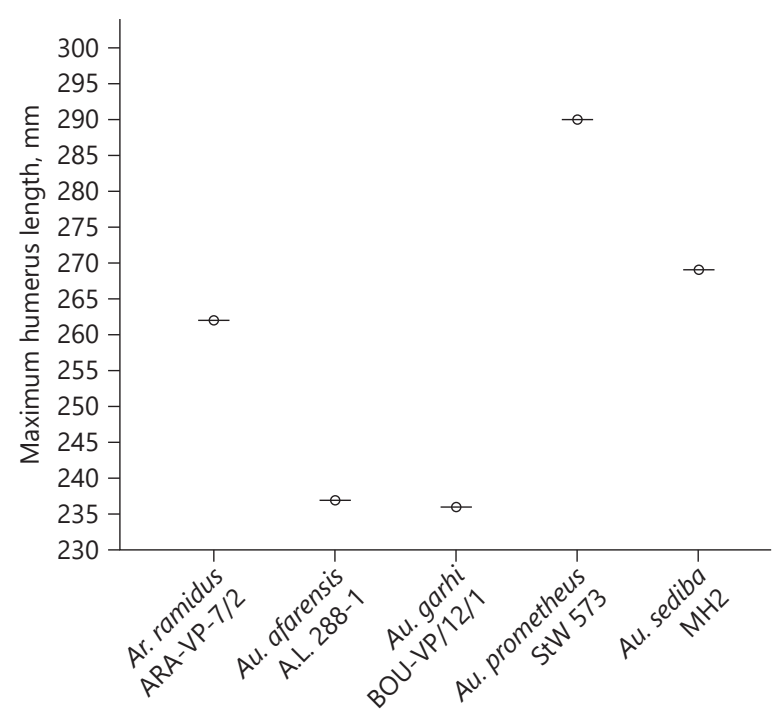

Fig. 6. Maximum humerus length in early hominins. That of StW 573 is longer than the other specimens, which sample the small body mass range of early hominins. Data from Johanson et al. [1982], Asfaw et al. [1999], Haile-Selassie et al. [2010], Churchill et al. [2013] and Heaton et al. [2019].

hominins, including Au. afarensis, but slightly smaller than some other South African Australopithecus (Fig. 5).

Humeral torsion, at $120^{\circ}$, falls within the range of orang-utans [Larson, 2007] and other early hominins, being lower than that of AL 288-1 and Sts 7, but slightly higher than MH 2 [Heaton et al., 2019], and considerably higher than ARA-VP-7/2 [112; Lovejoy et al., 2009b]. Modern humans, chimpanzees and gorillas have similar degrees of humeral torsion [Larson, 2015], unlikely to be accounted for by functional convergence, with high torsion in chimpanzees and gorillas likely to be related to their (distinct forms of) "knuckle-walking" quadrupedalism and high torsion in humans related to their frequent manipulation and throwing. Since orang-utans do not often knuckle-walk or engage in throwing, and manipulation is no commoner than in gorillas and chimpanzees, it follows that the moderate torsion in orang-utans and early hominins may reflect the primitive condition [and see Rose, 1989, Moya-Sola and Kohler, 1996, and pers. commun. from D. Pilbeam to R.H.C.). At $290 \mathrm{~mm}$ [Heaton et al., 2019], the left humerus of StW 573 has a longer maximum length than the very few other early hominin specimens available for comparison (Fig. 6). 


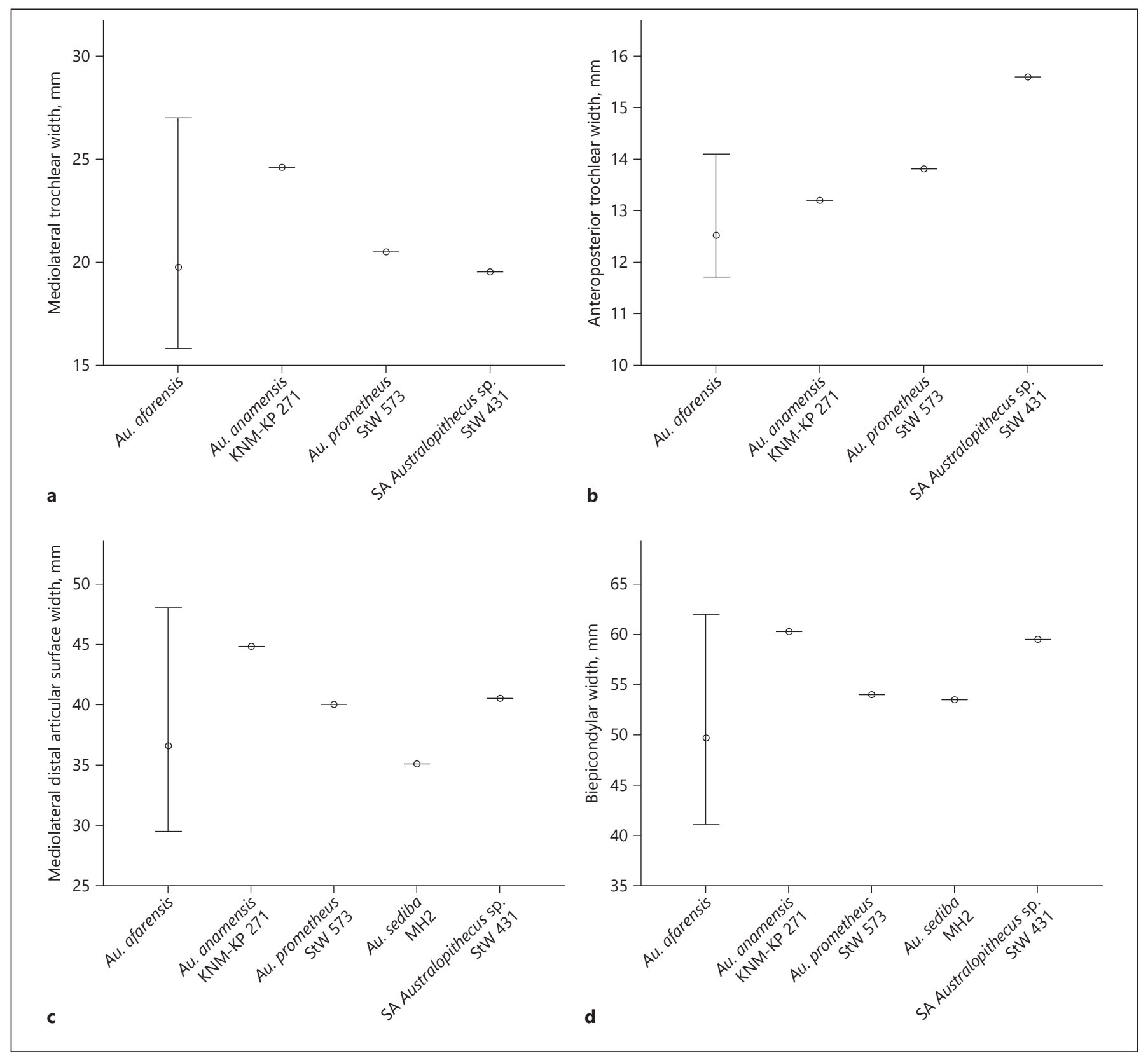

Fig. 7. a-d Distal humerus dimensions in early hominins. a Mediolateral trochlear width. b Anteroposterior trochlear width. c Mediolateral distal articular surface width. $\mathbf{d}$ Biepicondylar width. StW 573 (Au. prometheus) falls within the range of other Australopithecus (Au. afarensis comprises AL 288-1, AL 137-48a and AL 322-1 plus KSD-VP-1/1b for all dimensions apart from anteropos-

Its humerofemoral (86.6) and intermembral (85.5) indices, however, are quite similar to those of AL 288-1 (84.3 and 85.6, respectively) and ARA-VP-6/500 (89.1 and 89-91, respectively) [Heaton et al., 2019]. StW 573 falls within the range for humeral head diameter of $A u$. terior trochlear width). StW 431 is likely to be a male $A u$. prometheus. Circles represent means and bars maximum and minimum values. Data from Johanson et al. [1982], McHenry [1992], Haile-Selassie et al. [2010], Churchill et al. [2013] and Heaton et al. [2019].

afarensis but below that of other South African Australopithecus for which data are available (Fig. 6). Humeral length of StW 573 is greater than those of the other available specimens, which sample the smaller body mass range of many early hominins. 


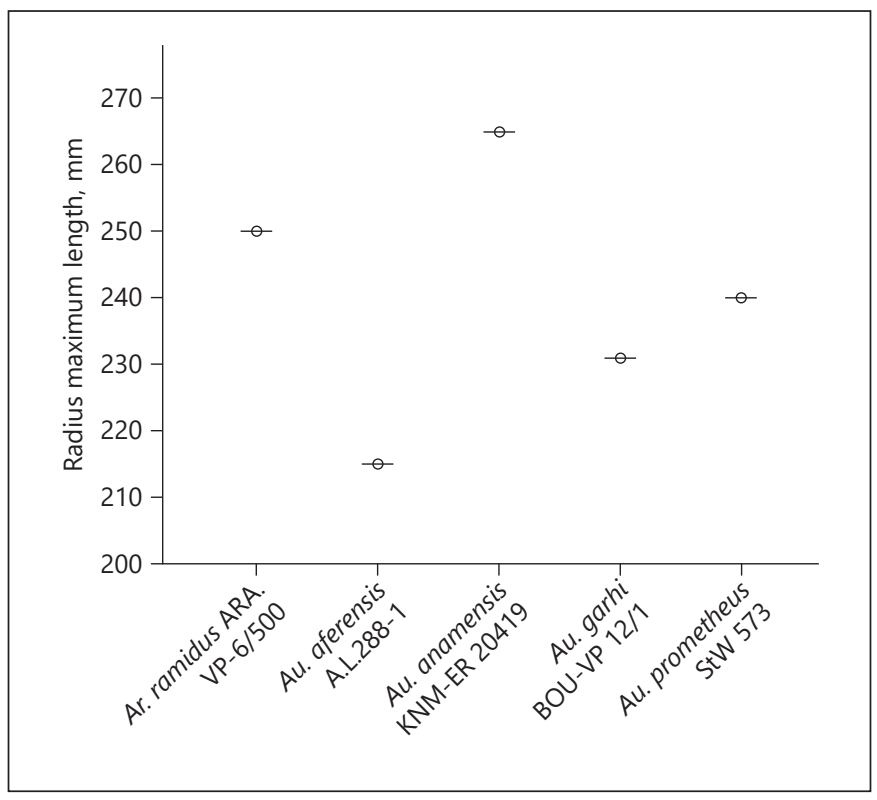

Fig. 8. Maximum radius length estimated for StW 573 and other early hominin specimens. All are estimates, although the radius of StW 573 is virtually complete [Heaton et al., 2019]. The StW 573 value is for the well-preserved left radius, estimated because of minor damage. Comparative data from Grine and Susman [1991], Heinrich et al. [1993], Asfaw et al. [1999] and Lovejoy et al. [2009a, b].

However, for distal humerus dimensions (Fig. 7a-d: mediolateral trochlear width, anteroposterior trochlear width, mediolateral distal articular surface width and biepicondylar width in early hominins), StW 573 falls within the range for Au. afarensis. However, the dimensions are lower than those for Au. anamensis, except for anterioposterior trochlear width, and lower than the probable male $A u$. prometheus StW 431, except for mediolateral distal articular surface width.

Physical data for other specimens are too incomplete to form any consistent pattern, and in our view, the only reasonable conclusion is that, where sample size is sufficient, StW 573 appears typical of early Australopithecus morphology. Indeed, distal humerus morphology is very variable in humans [Hill and Ward, 1988]. McHenry and Brown [2008] note that it is also heterogeneous in early hominins, and they suggest that morphological variability within early hominins indicates exploitation of different ecological niches. StW 573's lateral supracondylar crest (origin of musculus brachioradialis) is intact and substantial, implying power in pronation and elbow flexion. This is argued to be important for climbing, perhaps specifically vertical climbing [Hunt, 1991]. StW 573 has a salient lateral margin for the trochlear articulation, which may imply ulnar stability through reducing axial rocking, although this distinction may not be sufficiently major to imply active selection [sensu Lovejoy et al., 2016]. On the whole, therefore, the distal humerus morphology of StW 573 is consistent with a substantial degree of arboreality, as is more strongly evidenced by scapular morphology.

Radius, Ulna and Hand. At 240-250 mm maximum length [Heaton et al., 2019], the StW 573 radius plots within the range of estimated radial lengths for other early East African and South African hominins (Fig. 8).

The StW 573 brachial index is very similar to that of Gorilla and Au. sediba (one of the few other hominins where the index can be calculated with a degree of certainty [Heaton et al., 2019]. This lends weight to the argument that $\mathrm{Au}$. prometheus incorporated climbing behaviour into its locomotor repertoire, especially in combination with the relatively powerful musculus brachioradialis noted above. Like the Au. anamensis specimen KNM-ER 20419 [Heinrich et al., 1993], StW 573 has a "distinct anteromedial bevel" to its radial head, resulting in "eccentric placement of the capitular fossa” [Heaton et al., 2019, p. 173]. This morphology may indicate the importance of stabilizing the elbow when the arm is semi-pronated and hence when there is greatest advantage for $\mathrm{m}$. brachioradialis [Clemente, 1985; Heinrich et al., 1993], adding to the evidence for climbing behaviour which is strongly expressed. The ulnar keeling in StW 573, described by Heaton et al. [2019], may (as they imply) help resist forces generated across the elbow when the brachioradialis contracts [Drapeau, 2008]. Alongside this, both the left radius and ulna in StW 573 have a strong curvature (laterally in the radius, dorsally in the ulna [Heaton et al., 2019]. Forelimb curvature is variable in early hominins [Drapeau et al., 2005], but its presence is consistent with arboreality. The left and right ulnae display asymmetry, with the left being strongly dorsally curved but mediolaterally straight, while the right, again appearing mediolaterally straight, is less dorsally curved. At present, there is no conclusive evidence whether the asymmetry reflects healed premortem injury to the left arm [as suggested by Heile et al., 2018] or remodelling on the basis of handedness in vivo, a phenomenon far less common in non-human great apes [Schultz, 1937]. Indeed, the endocast shows that a left occipital petalia, an expansion of the occipital lobe into the right side of the cortex and a feature associated in living humans with handedness, was present [Beaudet et al., 2019a].

A radial neck that is long compared to the overall length of the bone (Table 2) is often associated with arbo- 
Table 2. Radial neck metrics of StW 573 and comparative sample

\begin{tabular}{llll}
\hline Specimen/taxon & $\begin{array}{l}\text { Relative radial neck thickness } \\
\text { ([anteroposterior neck diameter/ } \\
\text { anteroposterior head diameter] } \times 100)\end{array}$ & $\begin{array}{l}\text { Radial neck length (from the middle } \\
\text { of the proximal surface of the radial head } \\
\text { to the centre of the radial tuberosity), mm }\end{array}$ & $\begin{array}{l}\text { Relative radial neck length } \\
\text { ([neck length/maximum } \\
\text { length] } \times 100)\end{array}$ \\
\hline StW 573 & 69.9 & 34 & 14.2 \\
AL 288-1 & $\sim 63$ & 39 & $\sim 14.7$ \\
KNM-ER 20419 & $\sim 64$ & & 14.1 \\
Homo sapiens (mean) & $\sim 64$ & & 15.6 \\
Pan (mean) & $\sim 55$ & & 18.4 \\
Gorilla (mean) & $\sim 51$ & 58 & 12 \\
Pongo (mean) & $\sim 58$ & & \\
\hline
\end{tabular}

, estimated from plot. Left radius of StW 573 from Heaton et al. [2019]; radius metrics for Pan, Homo sapiens, AL 288-1 and the Allia Bay radius KNM-ER 20419 from Heinrich et al. [1993].

reality, as it indicates an increased moment arm of the elbow flexor musculus biceps brachii [Napier and Davis, 1959; Conroy, 1976; Harrison, 1989]. However, allometry may confound the signal [Reno et al., 2000], and we also note the variation among hominoid taxa reported by Heinrich et al. [1993], who also noted that Au. anamensis had an $\mathrm{m}$. biceps brachii moment arm more similar to Pan than Homo. The neck length index of StW 573 is very similar to that of KNM-ER 20419. It is possible that the similarity in neck length index between Pan, Homo and the two species of Australopithecus examined here has a phylogenetic basis. Nonetheless, the medially orientated radial tuberosity of StW 573 [Heaton et al., 2019] is consistent with high power in supination of $\mathrm{m}$. biceps brachii, a feature more in common with non-human apes than modern humans [Aiello and Dean, 1993], given other features of the forelimb which indicate a considerable degree of arboreality. Unfortunately, the epiphysis of the StW 573 distal radius is too damaged to make inferences about the adaptations of the wrist joint, which could have provided important evidence about range of motion and locomotion.

The StW 573 left ulna has a maximum length of 259 $\mathrm{mm}$ [Heaton et al., 2019], in comparison to the $278 \mathrm{~mm}$ of AL 438-1, Au. afarensis [Drapeau et al., 2005]. The StW 573 brachial index of 82.8 is very similar to that of G. gorilla, $80.6(n=22)$, lending weight to the argument that $A u$. prometheus incorporated substantial climbing behaviour into its locomotor repertoire. The StW 573 ulnar trochlear notch faces anteriorly, with a trochlear notch orientation index of 82.1 (using the index as defined in Churchill et al. [2013]) and an angle of $8^{\circ}$ [Heaton et al., 2019]. This morphology, derived compared to extant apes, is entirely consistent with that of other Australo- pithecus [Drapeau et al., 2005; Churchill et al., 2013]. It may reflect increased loading of the flexed elbow [Drapeau et al., 2005]. The function of the elbow flexors appears, however, to vary among Australopithecus. In StW 573, the mechanical advantage of musculus brachialis (as defined in Churchill et al. [2013]) is 0.139. This groups reasonably closely with those Australopithecus $(0.145 \pm 0.009)$ in Churchill et al.'s [2013] sample, but it is higher than that of Au. sediba (0.127), which is thought by those authors to have "relatively poor mechanical advantage for the elbow flexors" [Churchill et al., 2013, p. 4]. The musculus triceps brachii mechanical advantage (again as defined in Churchill et al. [2013]) of StW 573 is 0.068 , closer to the modern human mean $(0.065 \pm 0.007)$ than to Au. sediba (0.075) or the Australopithecus mean (0.081 \pm 0.003$)$. This implies less power in elbow extension in $A u$. prometheus compared to the other Australopithecus. However, the longer humerus length must be taken into consideration, and more extensive future analyses will shed further light onto the forelimb biomechanics of $\mathrm{Au}$. prometheus. With respect to locomotor signals in the proximal ulna of $A u$. afarensis and other Australopithecus, Drapeau [2008, p. 99] commented that it was "difficult to resolve issues about the specifics." The addition of $A u$. prometheus does little to help this, suggesting that Australopithecus show quite noisy variations on a common theme that incorporates a degree of arboreality (possibly employing different modes in different species) alongside terrestrial bipedalism.

As reported in Clarke [1998, 2002], the relative proportions of the thumb and fingers of StW 573 are modern-human-like, as with the AL 333/333w Au. afarensis hand [Alba et al., 2003]. This suggests that modern human-like hand proportions, as well as grasping capacities 


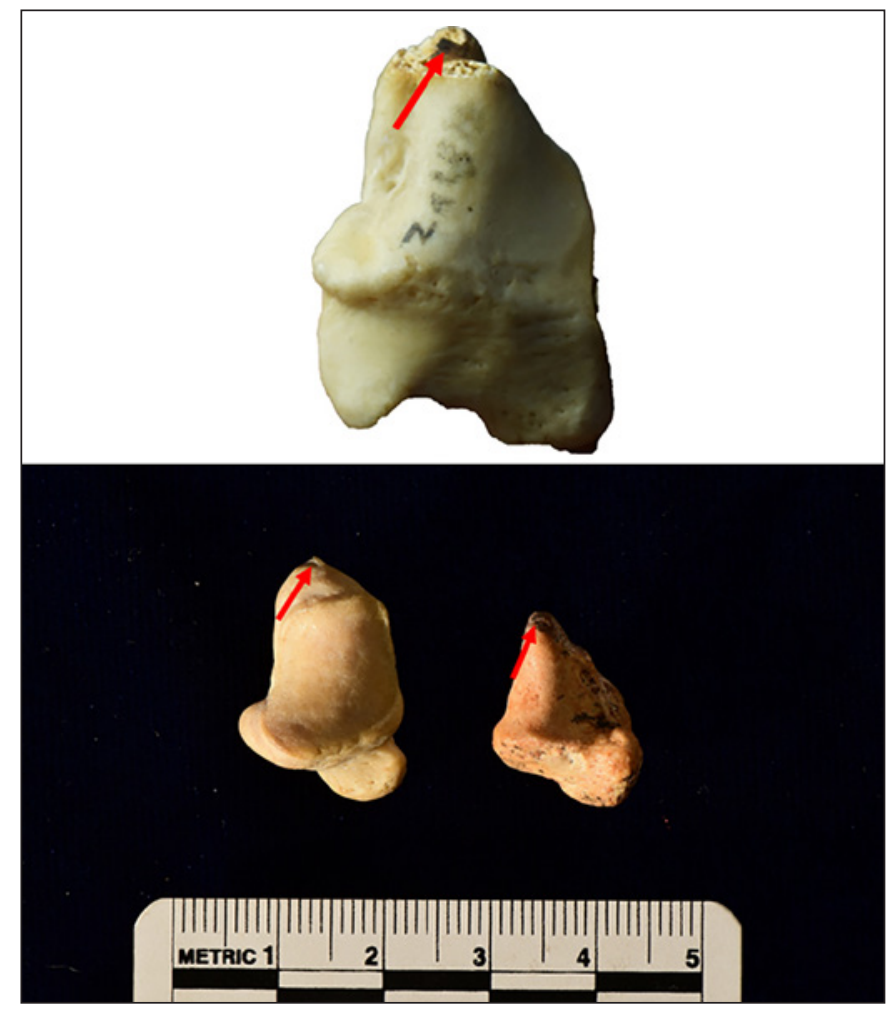

Fig. 9. Above, the trapezium of a gorilla. Below, the trapezium of StW 573 (right) compared to that of a human (left), Note the apical ridge (red arrows) in StW 573, which is more salient than it is in humans. Images courtesy Ronald Clarke.

[Clarke, 1998, 2002] had their origins in arboreal behaviour before they were exploited in more terrestrial hominins for tool use.

The StW 573 trapezium (Fig. 9) bears a salient apical ridge, a feature commonly present and marked in living gorillas. Trapezium morphology is highly variable in primates [Napier and Davis, 1959], so care must be taken in interpretation, but it is likely that the apical ridge, absent in humans, might help brace the thumb and its ulnar and radial carpometacarpal and metacarpophalangeal collateral ligaments against forced abduction [Glickel et al., 1999]. In gorillas, the apical ridge might therefore stabilize the pollex in abducted pinch grips during climbing, and we suggest that this would be similar in StW 573: in both cases, this would particularly benefit climbing on smaller diameter supports. Jashashvili et al. [under review] note that the hand is also characterized by a midcarpal joint form favouring stability rather than mobility.

\subsection{Functional Morphology of the Hindlimb}

Pelvis. The StW 573 pelvis (Fig. 3) requires retrodeformation prior to full analysis and comparison, as it is highly distorted and fragmentary on the left, with the dorsal surface largely comprised of matrix supporting paperthin bone. For that reason, it is not described in the special issue of Journal of Human Evolution on the StW 573 skeleton. However, on the right, the StW 573 pelvis is considerably less deformed, although some distortion exists in the lateral third of the iliac blade. Unlike the case in StW 431, the greater sciatic notch is open and symmetrical, and based on the method described in Simpson et al. [2008], it exhibits a female-like morphology, as the chord between the deepest inflection and the opening of the greater sciatic notch lies at the halfway point. The iliac pillar (Fig. 10) is evident in CT scans for three quarters of the height of the ilium, but it does not reach the iliac crest; the iliac pillar, as with other Australopithecus, lies closer to the anterior superior iliac spine than in modern Homo. It is strongly marked, indicating substantial craniocaudal loading.

The acetabular margin is complete and undistorted dorsally. The internal superoinferior diameter of the acetabulum is $41.3 \mathrm{~mm}$, compared to $34.7 \mathrm{~mm}$ in AL 288-1 [Johanson et al., 1982]. That of the acetabulum of StW 431 is difficult to assess accurately as the inferior rim of the acetabulum is missing, but it is approximately $40 \mathrm{~mm}$. and thus the femoral head of StW 573 is a close match for the acetabulum of StW 431. The Sts 14 os coxae and that of AL 288-1 are small, with small acetabulae, but come from much smaller individuals. Macho et al. [2020] claim that in visual comparison some features of the StW 573 ilium are more "chimpanzee-like" than that of StW 431. However, casts of the prepared StW 573 pelvis and attached vertebrae and the reconstructed StW 431 pelvis (Fig. 3) may be compared to ventral views of Pan, Pongo and Gorilla pelves taken from 3D models constructed from CT of random specimens we dissected for tendon length studies (Fig. 11). A relatively greater similarity of the StW 573 pelvis to that of Pan is not apparent to us on the basis of this figure. A recently discovered and reconstructed (but as yet undescribed) ischiopubic element of StW 573 is a close match also to the StW 431 os coxae. As can be seen in Figure 11 there is no indication in either of these fossils of the long and narrow ilium seen in both Pan and Pongo, and a better match is to Gorilla among extant great apes. Schultz [1930] provides the indices for $\mathrm{H}$. sapiens of ilium length/ischium length as 139.0 and ilium width/ilium length as 89.2. The corresponding indices for Pan (species indeterminate) are 199.4 and 62.2, for P. pyg- 
Fig. 10. Right, horizontal CT sections of the right ilium of the original StW 573 os innominatum fossil to show the extent of the iliac pillar. CT performed by Kristian Carlson. Approximate position of the pillar is marked as "IP." In 3 and 4, the iliac pillar appears to be displaced dorsally, and the approximate position is marked as "IP?" Left, the positions of these sections on a photo of a first-generation cast, by R.H.C.

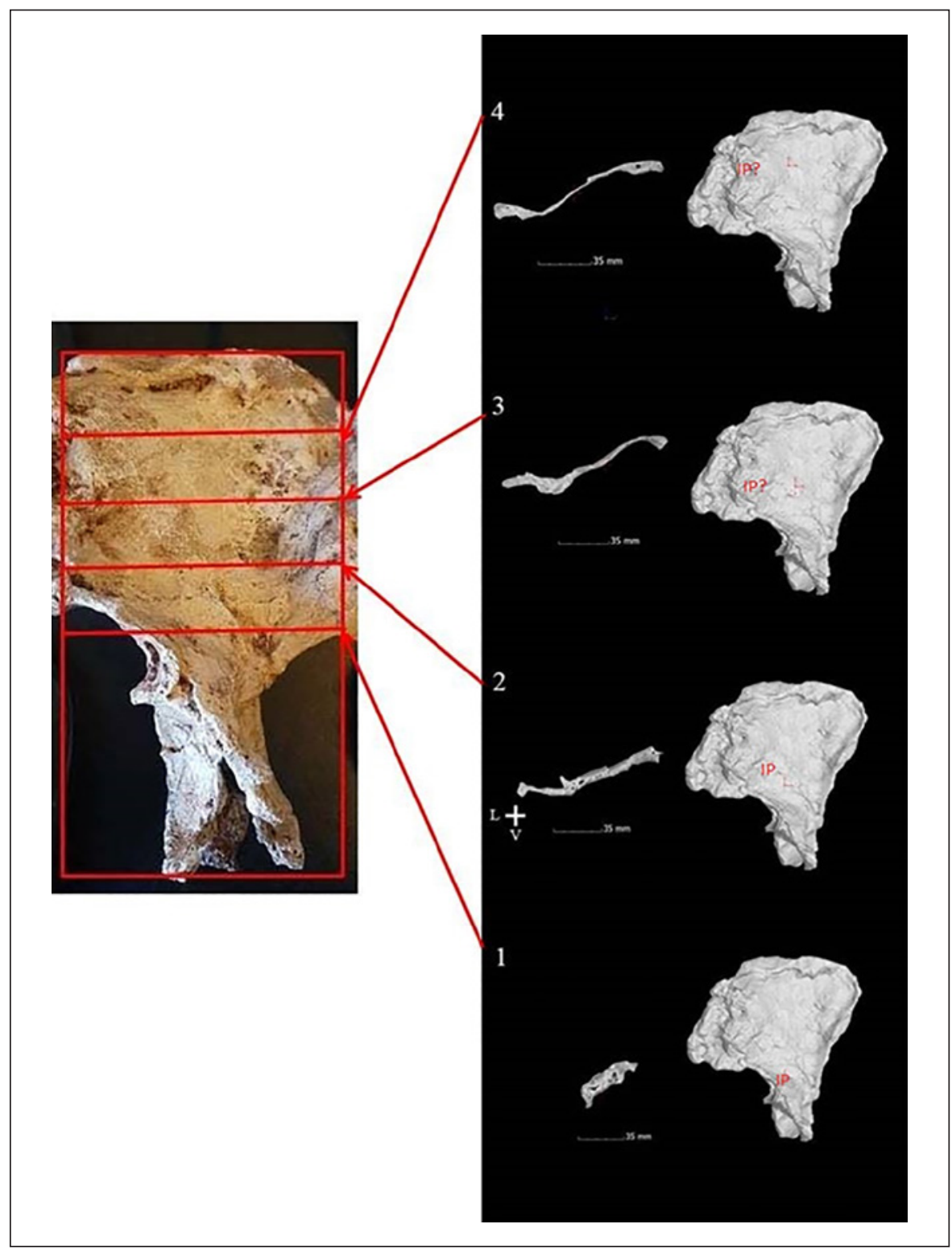

maeus 199.9 and 77.4, and for G. gorilla gorilla 185.1 and 89.7. The values were 195.5 and 86.0 in G. g. beringei, although he notes sample size was small. Schultz [1949, p. 414] thus remarked that "generally speaking, the pelvic topography of the gorilla is least removed from that of man, though there is still a very significant gap."

It is worth noting also that Hooton [1946] illustrates this similarity between gorilla and human. He states that the gorilla, because of its great bulk, "has very broad iliac blades curving around the pelvic inlet in a fashion recalling that of man" [Hooton, 1946, p. 110, and see his Fig. 9). Importantly, Fornai et al. [2021] have demonstrated that the probabilities of sampling sacral morphologies as dis- tinct as those of Sts 14 and StW 431 from a single species are as low as $1.3-2.5 \%$ (based on a human sample) or $0.0-$ $4.5 \%$ (for a sample of other great apes). There does thus now seem to be clear postcranial evidence that Member 4 Australopithecus samples more than one species, supporting the craniodental evidence presented by Clarke and Kuman [2019]. It is thus more parsimonious to accept the likelihood that StW 573 and StW 431 do indeed belong to a single second species, $A u$. prometheus, and thus that the postcrania are more closely comparable to each other than either is to $A u$. africanus Sts 14, than to posit a third species. 
Fig. 11. a Pelvis of a Pan troglodytes. b Pelvis of a Pongo pygmaeus. c Pelvis of a male Gorilla gorilla. In each case these are taken from CT meshes of the subjects dissected for our studies of tendon length and were zoo specimens. d A commercial cast of a female gorilla. e Pelves of StW 573 (above, unreconstructed) and StW 431 (below, reconstructed), courtesy of Ronald Clarke. The particular similarity of the pelvis of Gorilla to that of humans was noted by Schultz [1930, 1949].
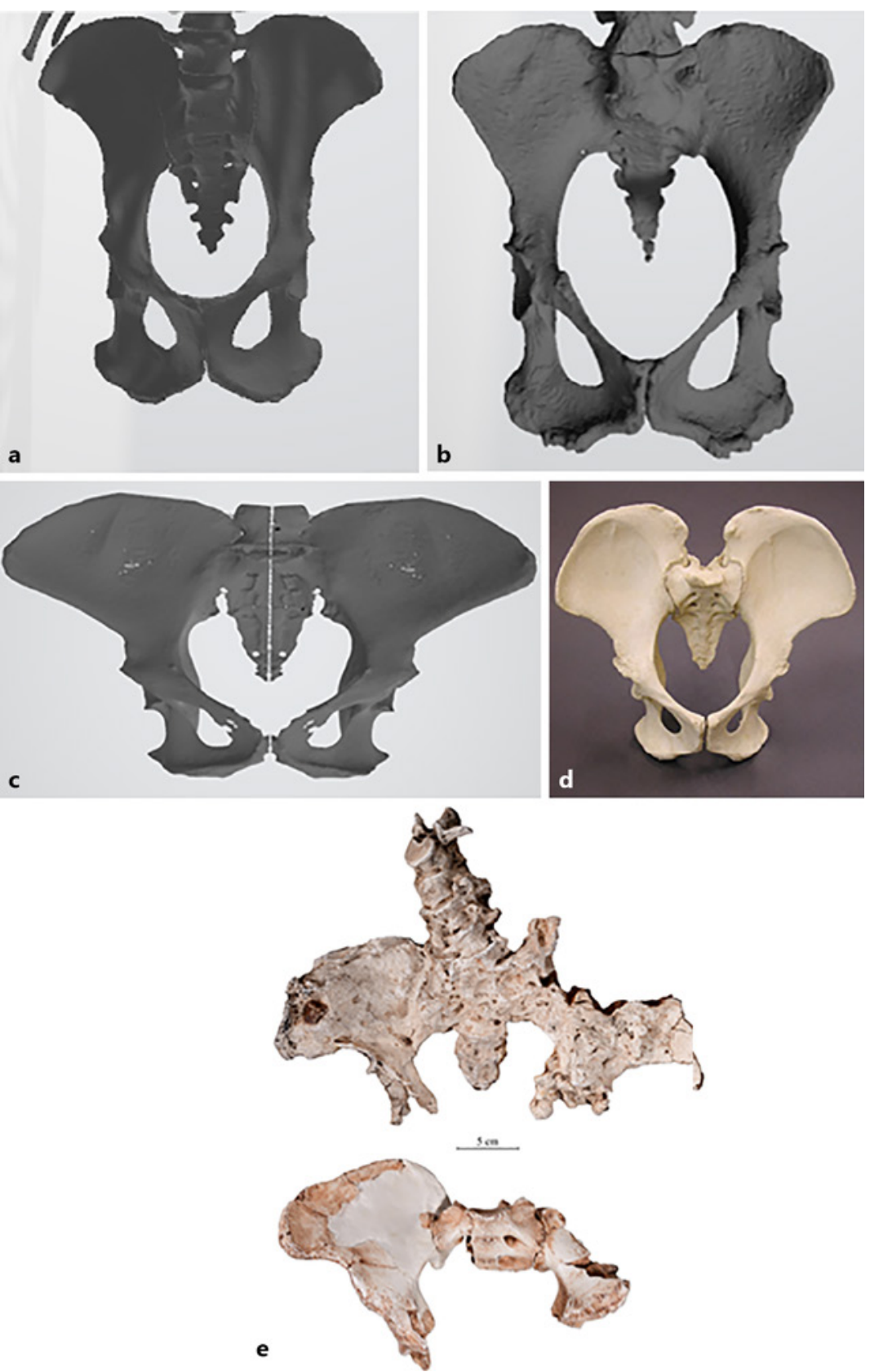

Kozma et al. [2018] calculated "dimensionless mechanical advantage" in the hip musculature of some early hominins, focussing in particular on the hamstrings in non-human great apes and monkeys. However, they make their contrasts primarily between "apes" and hominins, which rather obscures the shorter and broader ilium of Gorilla than Pan and Pongo, and the consequences, for example, for the extensor moment of the glutei.
Virtual tendon travel studies are an ideal way of assessing 3D moment arms about joints, as Goh et al. [2017, 2019] did for the hip, knee, ankle and foot of western lowland gorillas. Contrary to earlier studies which used dissection approaches, they found that these gorillas have very effective hip extensors even in extended hip postures, despite the high frequency of vertical climbing behaviour in this species. 


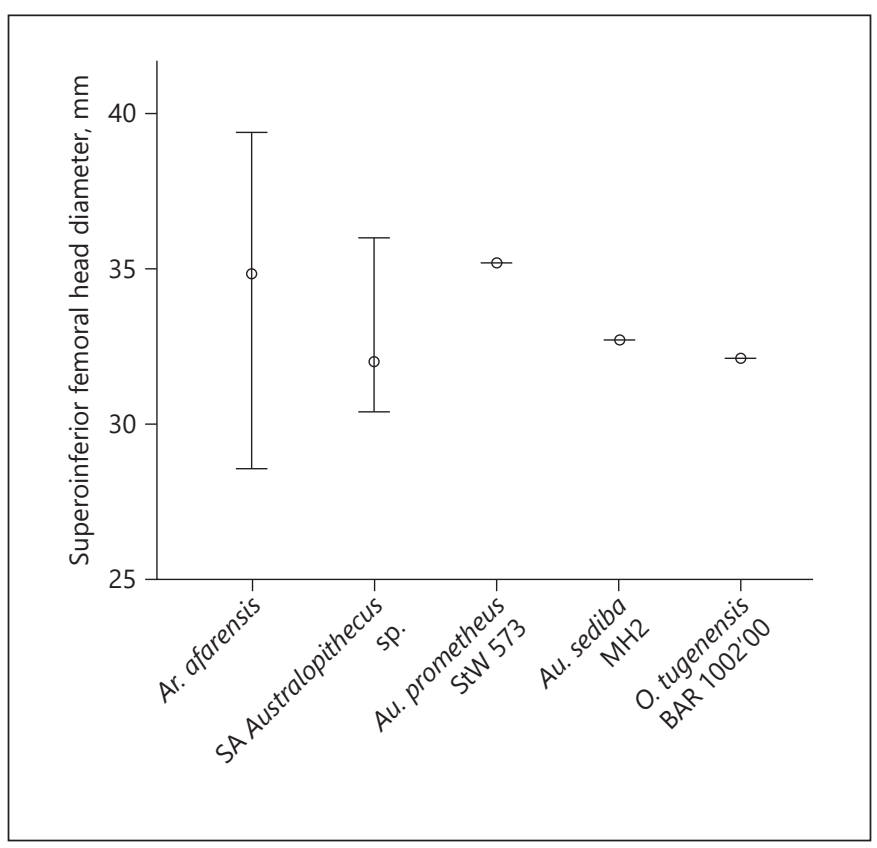

Fig. 12. Superoinferior femoral head diameters in early hominins. StW 573 value estimated [Heaton et al., 2019]. Circles represent means and bars maximum and minimum values. Comparative data as reported in DeSilva et al. [2013]. Southern African Australopithecus sp. comprises MLD 46, StW 25, StW 392, StW 403, StW 501, StW 522, StW 527 and StW 598. Note that a value is also provided in DeSilva et al. [2013] for StW 99 but is not included here because the specimen may be Paranthropus [Partridge et al., 2003].

Femur. The StW 573 femur shows very clear evidence of bipedalism, but equally, in most aspects, it falls well within the range of other Australopithecus. In femoral head diameter (Fig. 12), StW 573 has an estimated mean very similar to that of the $A u$. afarensis specimens in the comparative sample, with the exception of AL 288-1, but it is somewhat higher than the South African Australopithecus mean [data from DeSilva et al., 2013]. It has a human-like bicondylar angle of $11^{\circ}$ [Heaton et al., 2019]. Only a small portion of an intertrochanteric crest has been preserved [Heaton et al., 2019], but its presence is evidence of a strong iliofemoral ligament which would help maintain upright posture. The StW 573 platymeric index (anteroposterior/mediolateral shaft diameter immediately below lesser trochanter $\times 100$, which indicates the degree of anteroposterior flattening) is 77.9 [Heaton et al., 2019]. That of StW 573 falls slightly below the range for South African Australopithecus but above the range for Au. afarensis (Fig. 13).

StW 573 and the Australopith Bauplan

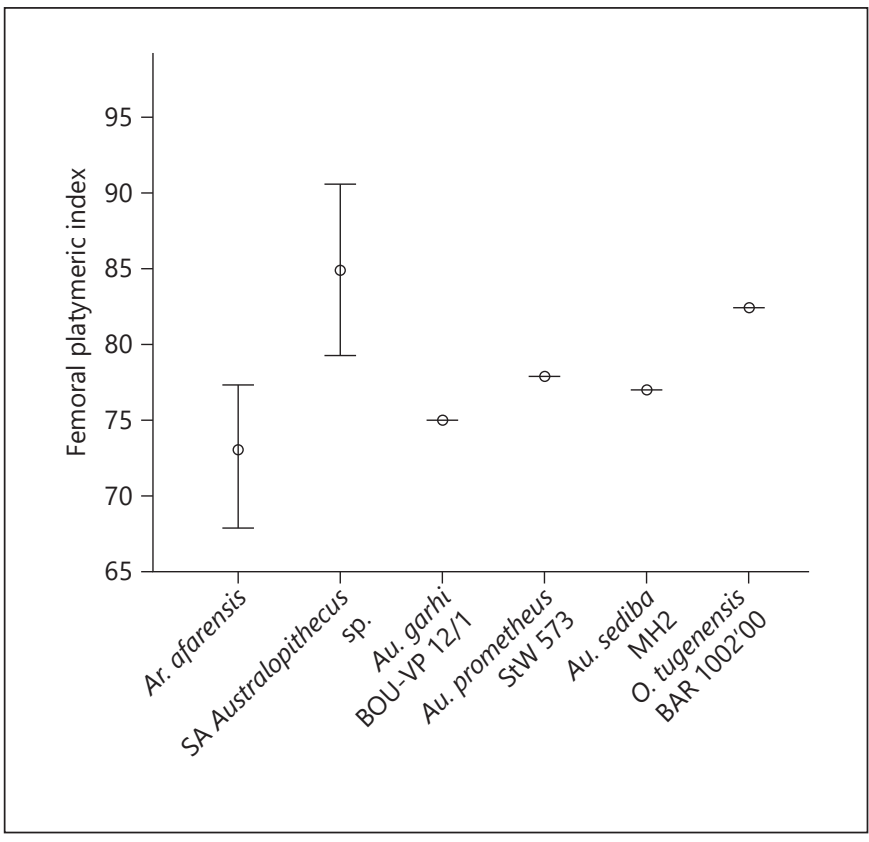

Fig. 13. Platymeric index of the femur in early hominins. Australopithecus prometheus (StW 573) value from Heaton et al. [2019]. Circles represent means and bars maximum and minimum values. Comparative data as reported in DeSilva et al. [2013] and Pickering et al. [under review]. Australopithecus afarensis comprises AL 288-1, AL 333-3, AL 211-1 and MAK-VP 1/1 [DeSilva et al., 2013]. Southern African Australopithecus sp. comprises StW 522 (as reported in DeSilva et al. [2013]) and StW 598 (as reported in Pickering et al. [under review]). Note that an estimate is also provided in DeSilva et al. [2013] for StW 99 but is not included here because the specimen may be Paranthropus [Partridge et al., 2003].

Platymeric indices in Pan and Gorilla [DeSilva et al., 2013] show a tendency towards a more rounded proximal femoral shaft. Ruff and Hayes [1983a, b] noted that the proximal femur of modern human Puerto Rican females is more platymeric than that of males, presumably as a response to relatively higher mediolateral forces. Westcott [2006] observed that the human femur becomes flatter anteroposteriorly during ontogeny, attributed to the greater mediolateral loads on the femur that occur with mature bipedal gaits. The pattern of platymeria in modern humans can of course not be assumed to apply to earlier hominins, especially more arboreal hominins. While the subtrochanteric shaft is more rounded in Orrorin tugenensis, StW 573 falls within the range of variation of adult modern humans and Australopithecus and is very similar to Au. sediba [Marchi et al., 2017] (Fig. 13). This would of course be consistent with a high degree of terrestriality. StW 598 has a more rounded shaft than StW 573 but StW 99 a more flattened one, probably because, 


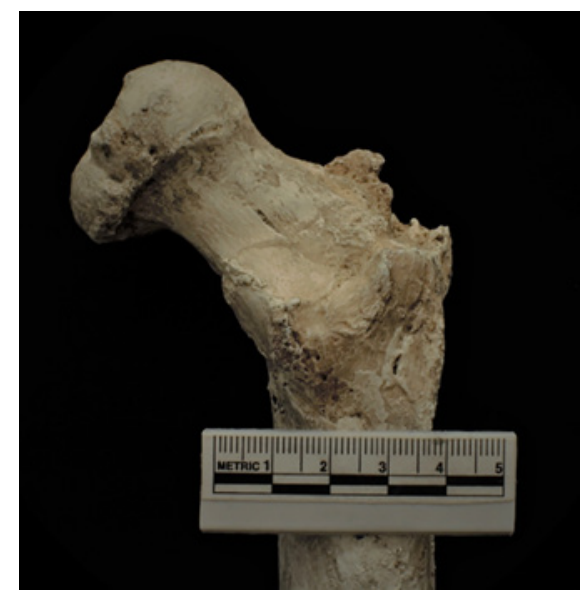

Fig. 14. Femoral neck and head of StW 573. Taken by R.H.C. from a first-generation cast.

according to R.J.C., it is most likely a Paranthropus from Member 5 (not Member 4) [Pickering et al., 2019]. Most Au. afarensis specimens are anteroposteriorly flatter [data from DeSilva et al., 2013].

Relative neck length and neck shape again fall within the range of variation of other Australopithecus [Heaton et al., 2019]. Given the preservation of the proximal femur (Fig. 14), biomechanical neck length in StW 573 is cautiously estimated here as approximately $55 \mathrm{~mm}$, below the South African Australopithecus mean (Fig. 15; comparative data from DeSilva et al. [2013]).

It is well within the range of variation of early hominins as a whole and occupies an intermediate position between modern humans/gorillas and chimpanzees. Biomechanical neck length is a proxy for moment arm of the hip abductors musculi gluteus minimus and medius [Rein, 2020], and the similarity in biomechanical neck length in StW 573 and other Australopithecus indicates that the $A u$. prometheus hip was similarly stabilized during bipedal walking.

In the distal femur (Fig. 16), the lateral femoral condyle of StW 573 is posteriorly "elliptical," as is also reported for KSD-VP-1/1 Au. afarensis [Lovejoy et al., 2016]. Similar to the human lateral femoral condyle, StW 573 has a relatively rounded posterior/dorsal section and flat anterior/ventral section. StW 573 has a deep patellar groove and shows a high lateral wall for patellar retention [Heaton et al., 2019], as is also the case, for example, in KSD-VP-1/1 [Lovejoy et al., 2016] and Au. sediba [DeSilva et al., 2013]. That StW 573 was a habitual biped is also reinforced by the evidence of a strong marking for mus-

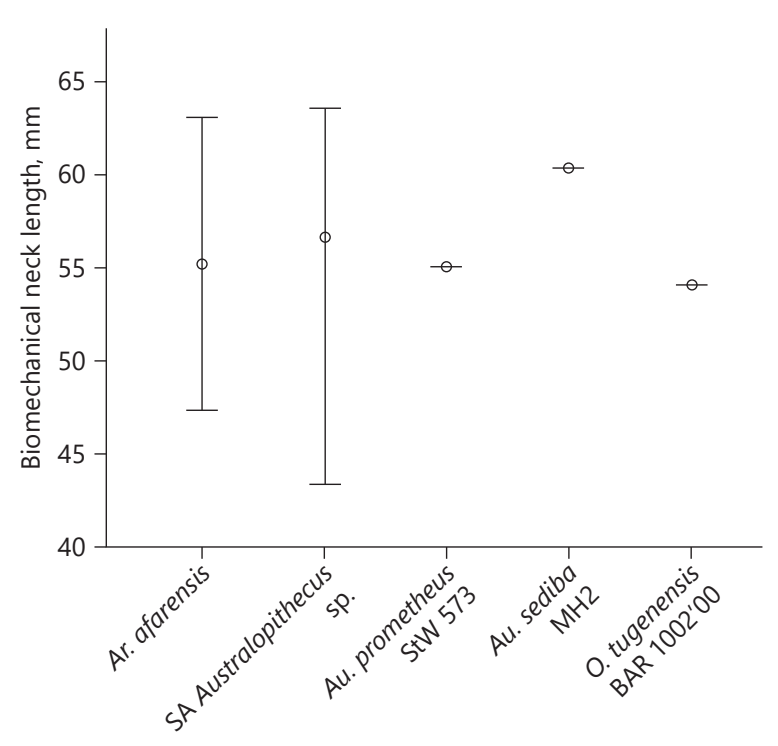

Fig. 15. Biomechanical femoral neck lengths in early hominins. StW 573 value estimated. Circles represent means and bars maximum and minimum values. Comparative data as reported in DeSilva et al. [2013]. Australopithecus afarensis comprises AL 2881 and AL 333-3. Southern African Australopithecus sp. comprises MLD 46, Sts 14, StW 522 (estimated) and StW 598. Note that a value is also provided in DeSilva et al. [2013] for StW 99 but is not included here because the specimen may be Paranthropus [Partridge et al., 2003].

culus popliteus [Heaton et al., 2019], a muscle that in humans helps "unlock" the knee from its posture in upright bipedal standing to permit recommencement of walking (see below).

It is worth noting that while the relative geometry of the lateral and medial femoral condyles in at least some $\mathrm{Pan}$ is very similar (Fig. 16) the asymmetry seen in StW 573 is to some extent echoed by those of some lowland gorilla individuals. This would itself increase knee stability in full extension and would be consistent with the finding of Goh et al. [2017] that hip extensors in Gorilla retain high extensor moments even near full extension, enabling effective bipedal standing and quite likely propulsion.

Tibia and Fibula. StW 573 has an anterioposteriorly longer, concave medial tibial condyle and a shorter, less concave lateral condyle, matched by an anterioposteriorly long, convexly rounded section on the medial femoral condyle but an (again anterioposteriorly) anteriorly flatter lateral condyle (Fig. 17). 

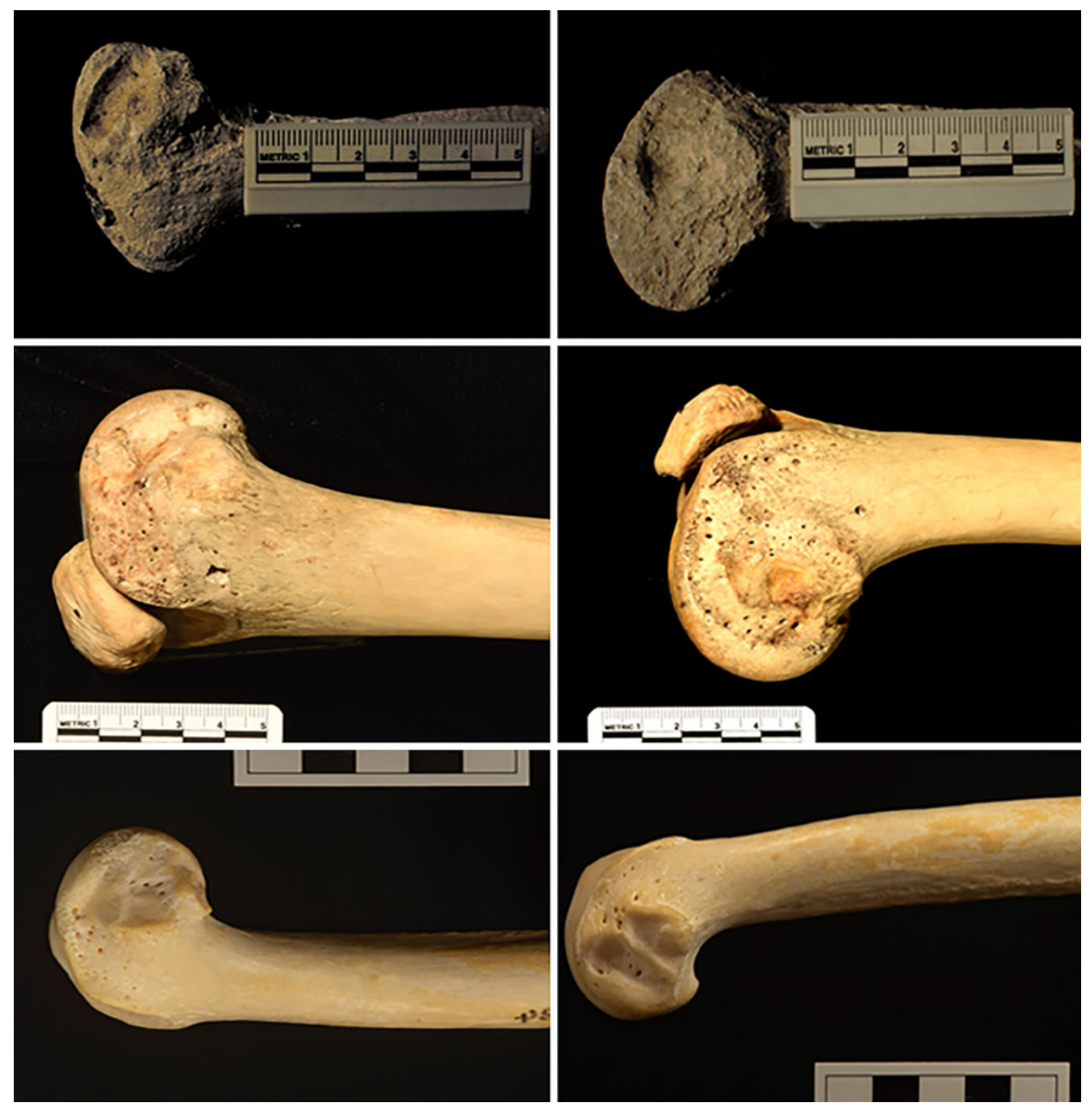

Fig. 16. Lateral (left) and medial (right) femoral condyle shape. Top, StW 573. Middle, a Gorilla gorilla individual. Bottom, a Pan troglodytes individual. Images of StW 573 made by R.H.C. from a first-generation cast. Other originals in the Liverpool University collection, courtesy of Kristiaan D'Août.

The StW 573 intercondylar eminences (height: medial approx. $7.5 \mathrm{~mm}$, lateral approx. $6 \mathrm{~mm}$ ) are marked, as in modern humans. There is a similar relationship between relative lengths of the tibial condyles to other Australopithecus (Fig. 18). The shape of the StW 573 tibial condyles (Fig. 19) is similar overall to those of $A$ u. anamensis, but $A u$. afarensis is more divergent, possibly related to its high valgus angle.

This notwithstanding, Organ and Ward [2006] found no difference in lateral tibial condyle geometry between
StW 514a (not included in our data set because the medial condyle is incomplete anteroposteriorly) and Au. afarensis. The difference in lengths between the two condyles is the bony basis of the "locking" mechanism of the knee [see, e.g., Dye, 1987, and Lovejoy, 2007]. In this mechanism, the condyles and cruciate ligaments form a four-bar linkage. In knee extension, because of the flatter condylar morphology of the ventral part of the lateral condyles, the lateral condyle ceases sagittal rotation before the medial condyle. "Rollback" ensues, compressing 


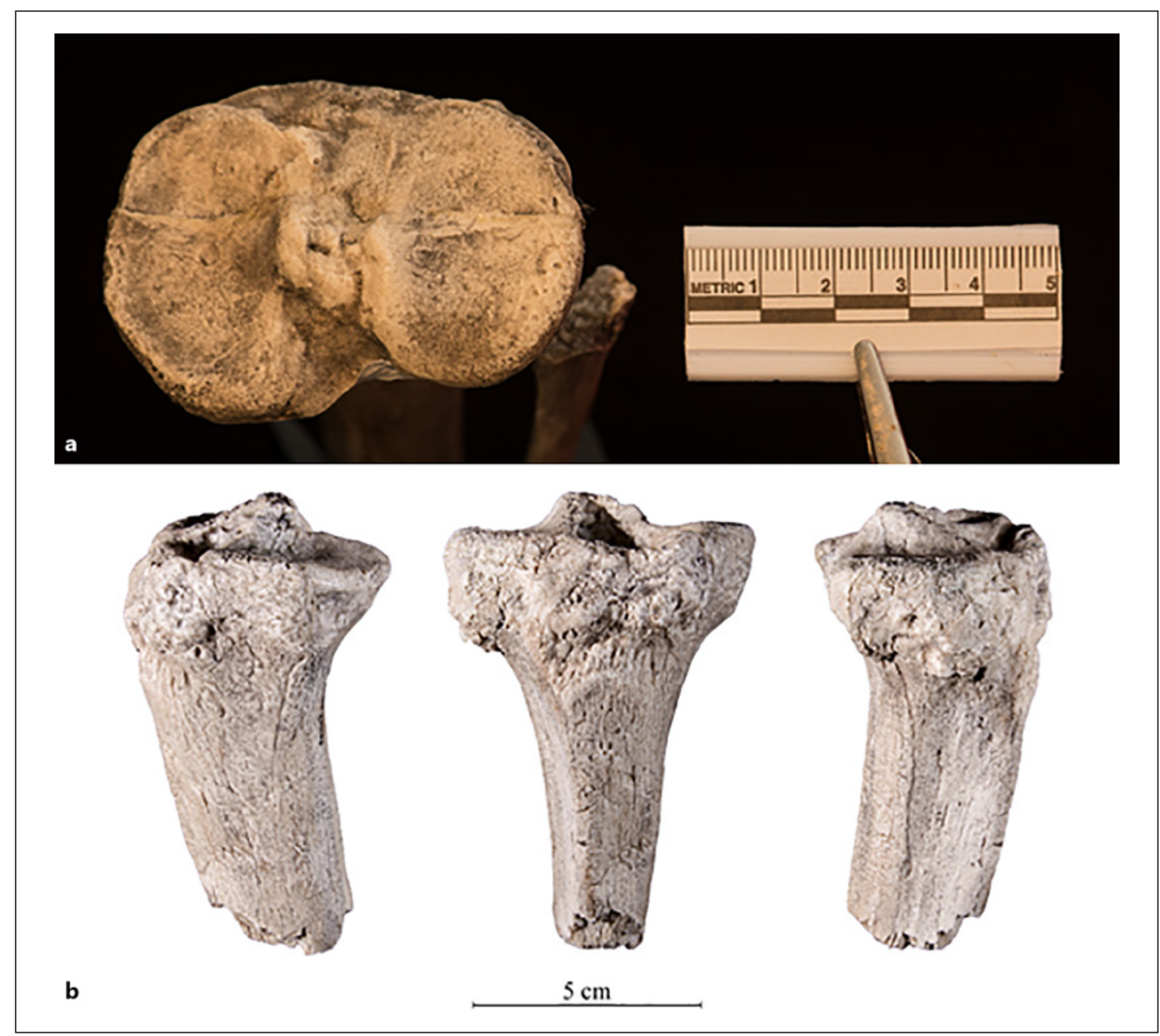

Fig. 17. Tibial condyles of StW 573. a From above (first-generation cast, by R.H.C.). b Medial, lateral and frontal views (original, courtesy of Ronald Clarke).

the lateral meniscus and further immobilizing the lateral condyle. Thus, a passive coronal rotation of the knee results, spiralizing fibres in the cruciate ligaments and stabilizing the knee. This allows standing with minimal expenditure of muscular energy for balance, but a strong $\mathrm{m}$. popliteus is required to reverse the rotation and "unlock" the knee.

The StW 573 tibial diaphysis is laterally flattened, with a platycnemic index (mediolateral diaphyseal width at nutrient foramen/anteroposterior diaphyseal width at nutrient foramen $\times 100$ ) of 64.5 [Heaton et al., 2019], compared to the Australopithecus index range of 64.768.4 , a modern human index of $64.8-84.7$, a gorilla index of 58.1-81.1 and a chimpanzee index of 55.7 to 73.0 [data from Marchi et al., 2017]. Distal tibial shape (maximum anteroposterior depth of the distal tibia/maximum mediolateral width of the distal tibia $\times 100$ ) for StW 573 falls within the range of other Australopithecus (Fig. 20).

Some non-human great ape-like traits have already been noted in the StW 573 tibia and fibula, relating to the tibial interosseous border, attachment of the musculus soleus on the fibula and shape of the tibiotalar joint [Heaton et al., 2019]. On the fibula, the StW 573 fibulotalar articulation is orientated inferiorly [Heaton et al., 2019]. An "ape-like downward orientation" is noted for the fibulotalar articular facets of Au. afarensis from Hadar, interpreted as evidence for high ankle joint mobility [Marchi, 2015, p.146], an interpretation that can be extended to StW 573. Tibiotalar joint geometry for Australopithecus other than StW 573 is discussed by Carlson et al. 


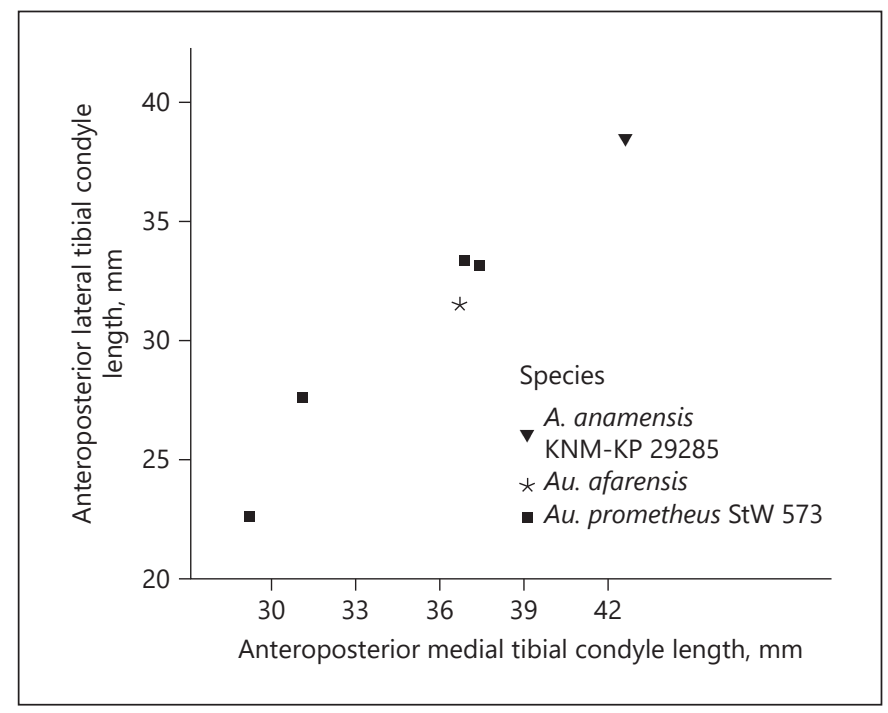

Fig. 18. Relative lengths of the tibial condyles. These are similar among Australopithecus (Spearman's correlation $r=0.94, p=$ 0.005). StW 573 data from Heaton et al. [2019]. Comparative data as reported in DeSilva et al. [2018]. Australopithecus afarensis comprises AL 129-1, AL 288-1, AL 333x-26 and AL 330-6.

[2020] and is not reviewed extensively here. The StW 573 tibiotalar articular surface shows some fracturing and exfoliation, so confidence in measurements cannot be high, but shape (mediolateral anterior width/mediolateral posterior width) seems relatively high (ratio of 1.5), suggesting a mediolaterally wider anterior surface than other South African Australopithecus. Some doubt exists as to the appropriate comparative sample [Carlson et al., 2020], but if correct, this might have given relatively free mediallateral deviation of the foot on the crus, which would serve arboreal bipedalism better than terrestrial.

The morphology of the available footbones has been discussed by Clarke and Tobias [1995] and Deloison [2003], and the metrics reported at length by Deloison [2004]. As noted above, since both hands and feet have very high degrees of freedom, with multiple joints crossed by many active and passive soft tissues, they are now regarded as characterized by neurobiological degeneracy and joints may be recruited by motor control systems in different combinations, step-to-step, grasp-to-grasp [see, e.g., Latash et al., 2002; Seifert et al., 2016]. Functional interpretation is thus highly complex and outside the remit of this review. Significance of degeneracy in the hands and feet for hominins is discussed in McClymont et al. [under review]. Whether any morphological differences

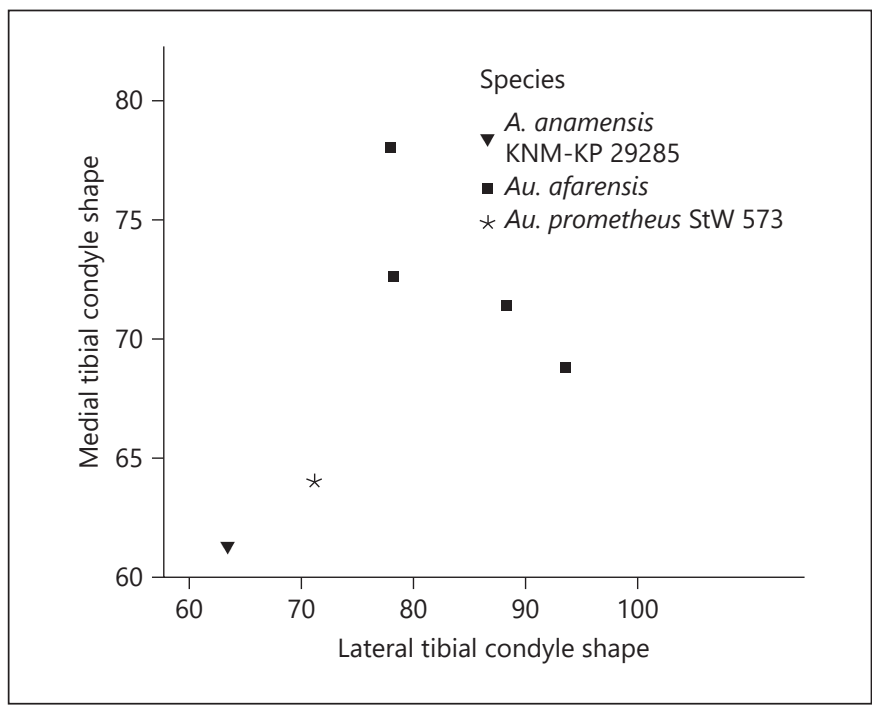

Fig. 19. Tibial condyle shape (mediolateral width/anteroposterior width $\times 100$ for each condyle). The shape of the StW 573 tibial condyles is similar overall to those of $A u$. anamensis, but $A u$. afarensis is more divergent, especially in medial condyle shape. StW 573 data from Heaton et al. [2019]. Comparative data as reported in DeSilva et al. [2018]. Australopithecus afarensis comprises AL 129-1, AL 288-1, AL 333x-26 and AL 330-6.

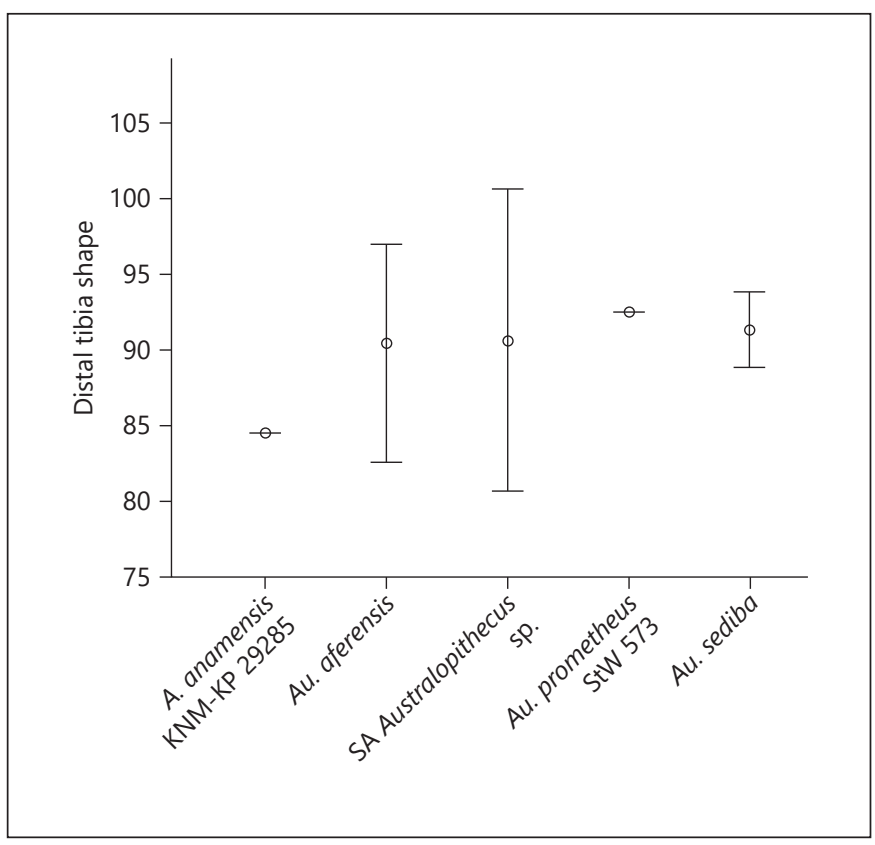

Fig. 20. Distal tibial shape. StW 573 falls within the range of other Australopithecus. StW 573 data from Heaton et al. [2019]. Comparative data as reported in DeSilva et al. [2018]. Southern African (SA) Australopithecus sp. comprises StW 358 and StW 567. Australopithecus sediba comprises $\mathrm{MH} 2$ and $\mathrm{MH} 4$. 


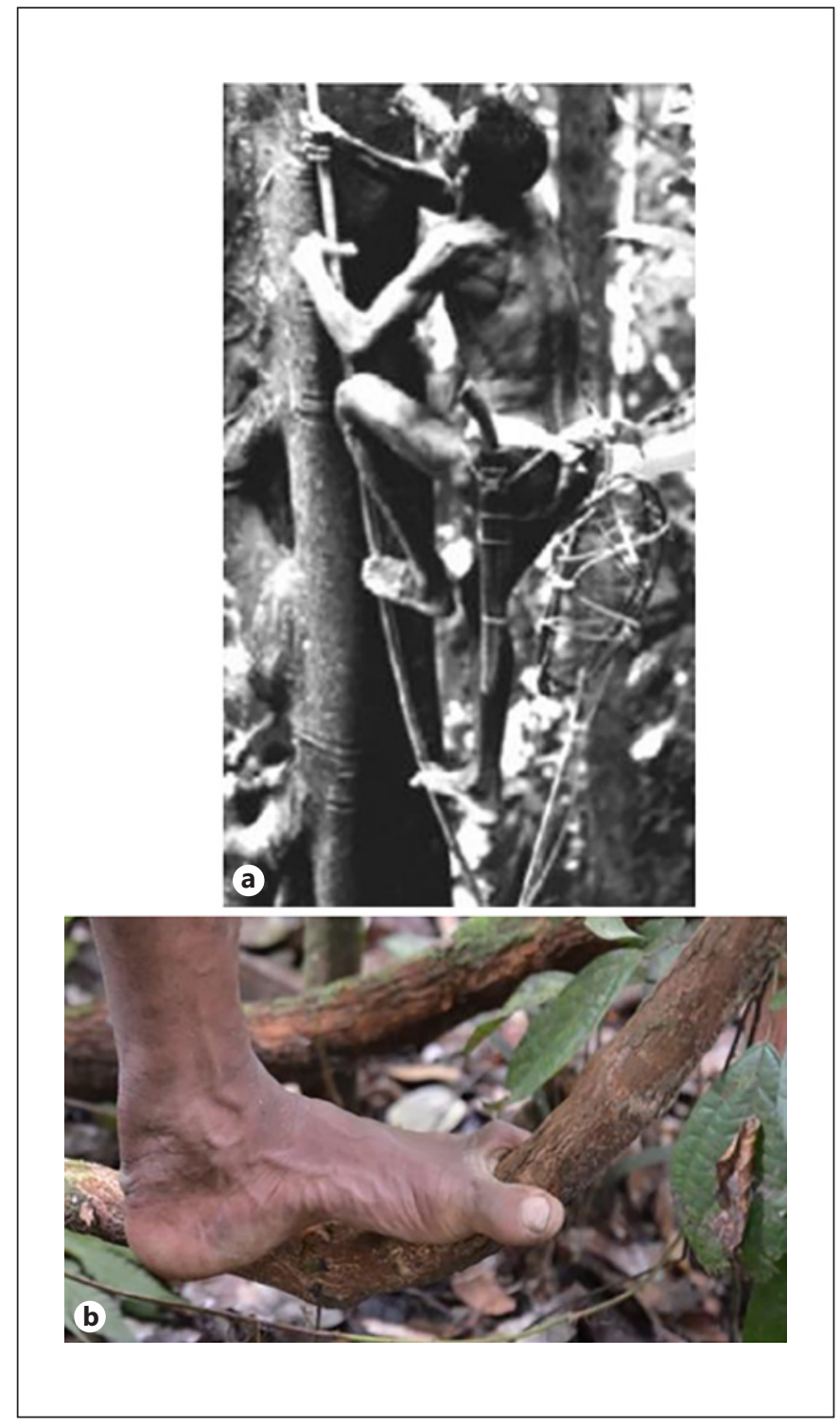

Fig. 21. a Archival image of an indigenous arboreal forager climbing a thin vine using flexed elbow postures and hallucal grasp (courtesy of Kirk Endicott). b An indigenous Batek arboreal forager demonstrating his hallucal grasp for climbing a small vine (video frame, courtesy of Vivek Venkataraman).

from modern human footbones such as those reported by Deloison [2004] offered significant advantage in arboreal climbing remains to be determined, but this would require analysis of a sample which includes human climbers such as the Twa (more below). Figure 21 shows that modern human indigenous climbers can certainly use the hallux to grasp small vines powerfully enough to support vertical climbing.

\section{Au. prometheus: Evidence for a Common Australopithecus Bauplan and Fundamental Niche}

Throughout this contribution, we have observed that, for most of the metric traits examined, StW 573 falls within the range of variation (non-size-adjusted) for early hominins, and specifically Australopithecus, as a whole. These skeletal similarities suggest a common Australopithecus locomotor bauplan, reflecting a similar fundamental niche, suggesting that Australopithecus of different species had similar potential niches, incorporating competent terrestrial and arboreal bipedalism, to greater or lesser degrees. We agree with McHenry and Brown [2008] to the extent that morphological variability between individual early hominin fossil skeletons, or skeletal elements, may indicate exploitation by those individuals of different realized niches, but fundamental niche appears to be similar.

The postcranial evidence reported in Heaton et al. [2019] and Carlson et al. [2020] and reviewed and examined further here, suggests that $A u$. prometheus was competent arboreally, a conclusion reinforced by the innerear mechanism, atlas cranial facet orientation and carotid foraminae of StW 573 [Beaudet et al., 2019a, b, 2020]. The lateral semicircular canal is mediolaterally large, as in non-human great apes but not Homo, although the apical part of the cochlea has loose turns, resembling the case in humans. The superior articular facets of the atlas are more concave than in Homo, and the inferior articular facets are more vertically inclined, which would have been likely to constrain motion of the head in the transverse plane. The small cross-section of the transverse foramina and left carotid canal suggest relatively low blood perfusion of the brain. All these together suggest that the ability to make the fine adjustments of unsupported bipedal gait required for long-distance terrestrial walking (striding) may have been limited [and see Pontzer, 2017]. This interpretation is in agreement with the conservative relative proportions of limb segments stressed by Heaton et al. [2019] and Carlson et al. [2020], despite the unequivocally human-like functional anatomy of the knee, which is clearly adapted for stability in extended postures, whether static or mobile. This is further evidence that australopiths, at the time of formation of the Laetoli footprint trails, used extended rather than flexed postures of the lower limb during bipedal walking.

Ward et al. [2001] suggest, largely on the basis of a parasagittal set of the talocrural articulation, that the eastern African Au. anamensis, slightly older than StW 573, was predominantly a terrestrial biped, but they acknowl- 
edge it may have included substantial arboreality in its locomotor and postural repertoire. Contemporaneous with StW 573, Au. afarensis clearly retained traits associated with arboreality [Stern and Susman, 1983]. If directional selection was operating to remove "anachronistic" arboreal adaptations from the Australopithecus form [Ward, 2002, 2013], or even if they remained selectively neutral, it might be considered unlikely to persist in different species across a period of one million years. Further, this might be thought to suggest that retention of forelimb adaptations suitable for climbing were retained by stabilizing selection because they allowed a large fundamental niche to be occupied, characterized by effective arboreal, as well as terrestrial, foraging. This would again be consistent with expectations from neurobiological degeneracy theory [Seifert et al., 2016].

\subsection{Plasticity at Intraspecific and Higher Taxonomic Levels}

The variation evident in the tribe Hominini, with large metric ranges in even single species, points to considerable intraspecific plasticity, alongside sexual dimorphism. Examining and understanding this plasticity is vital to considering the realized, rather than simply fundamental, niche. Inevitably, when interpreting the hominin fossil record, attention is focused on locomotor and postural evidence garnished from bone morphology, as it is usually impossible to consider soft tissue, thoroughly. Yet soft tissue has the potential to be more plastic and hence responsive to environmental subtleties. Fossil studies that reveal the bone architecture of fossil specimens that supported the soft tissue force application throughout life, are very valuable [Kivell, 2016; Chirchir, 2019]. Further valuable to the understanding of a realized niche in fossil specimens are studies of soft tissue architecture in extant great apes. A good example of this comes from the ankle, a region which we stated above provides essential information about arboreality. DeSilva [2009] argued that the human ankle joint was incapable of dorsiflexion to the extent required for "chimpanzee-like" vertical climbing, a view that has gained traction [e.g., Lovejoy et al., 2016], despite other research [Venkataraman et al., 2013] that showed that modern Twa hunter-gatherers, with typical human values for the talar facet of the tibia, can nevertheless achieve high ankle dorsiflexion and engage in vertical climbing since they tend to have longer fibres in the gastrocnemius muscle than neighbouring, non-climbing agricultural communities. Further, Holowka et al. [2017] have argued that DeSilva's [2009] estimates of ankle dorsiflexion in chimpanzee vertical climbing were probably erroneously high and an artefact of his method. They observe that chimpanzee quadrupedal walking is characterized by higher ankle dorsiflexion angles than typical of human bipedal walking. Thus, the linkage of talar facet morphology in chimpanzees with vertical climbing argued by DeSilva [2009] may now be largely unsustained.

Care must be taken in interpreting trabecular architecture, as Tsegai et al. [2018] found that differences in the trabecular bone volume fraction differences between forelimb and hindlimb in humans and chimpanzees did not clearly reflect locomotor loading. However, they noted that degree of anisotropy was more likely to reflect locomotor loading than species. Thus, we might speculate that internal femoral head architecture in hominins might also respond to activity characteristics, giving findings similar to those recorded at Sterkfontein by Georgiou et al. [2020], and confirmed in the metatarsals of hominins [Patel et al., 2018]. Thus, arboreal foraging of some kind remains within the human fundamental niche [Kraft et al., 2014]. This demonstrates the importance of plasticity - the ability to adapt musculoskeletal anatomy during development to enhance function in the realized niche to all great apes, including humans, which is a useful tool when evaluating the locomotor performance of fossil hominins. Indeed, long ago, Keith [1934] viewed plasticity as crucial in great ape evolution:

The presence of big-bodied primates in the Miocene indicates that a branch of the higher primates had then entered a period of evolutionary plasticity and was undergoing profound functional and structural changes. It was in this plastic period that I suppose the human line to have separated from that of the great anthropoids. [Keith, 1934, p. 20]

Here Keith [1934] refers to evolutionary, rather than ontogenetic plasticity. Whitaker and Bender [2010] and Seifert et al. [2016] show how increased evolvability driven by neurobiological degeneracy at gene level allows taxa to respond quickly to climate and environmental change.

Thus, paleoanthropological interpretations could be enhanced by greater acknowledgment that fundamental and realized niches of species and higher taxa are not identical, and that realized niches change according to environmental contexts. Those of us who study fossils can rarely carry out "laboratory experiments on the effect of morphological variation on behavioural performance" [Wainwright, 1991, p. 680], except by analogy to closely related species amenable to experiment, such as ourselves (see below). However, we can do so in silico, as we will again discuss below. 


\subsection{Palaeoecology of StW 573 in Relation to Au.}

anamensis and Laetoli Au. afarensis

The taphonomic evidence [Clarke, 2019a] is clear that StW 573 was found immediately below its habitat, most likely hilly, rocky shrubland/bushland, with areas of denser woodland or forest in the valley bottom [Pickering et al., 2004], associated with the Blaaubank water course, which would have been much larger than the stream that exists today. This is thus the realised habitat niche of StW 573. More work is required to reconstruct its dietary niche fully - important when considering posture alongside locomotion - but the toothwear in StW 573, with particularly heavy wear on the lingual aspect of the anterior dentition closely resembles that in available $\mathrm{Au}$. anamensis dentitions [Clarke and Kuman, 2019]. In living primates, such wear has been associated by Koyabu and Endo [2010] with eating fruits with hard pericarp. The realized dietary niche of StW 573 is thus likely to have incorporated foraging for arboreal resources. Early studies by Beaudet et al. [2021] using the Diamond synchrotron suggest that StW 573 suffered two bouts of severe dietary stress in childhood, again consistent with (but not necessarily due to) reliance on low-quality, seasonally deficient food resources.

The fundamental niche of Pliocene Australopithecus seems generally to have comprised a mix of $\mathrm{C} 3$ and $\mathrm{C} 4$ resources in a "mosaic" habitat. A C3-dominated diet or a diet with a small $\mathrm{C} 4$ component has been inferred for both $A u$. anamensis and Ar. ramidus, with $A u$. anamensis associated primarily with woodland/bushland/shrubland with a smaller local component of forest [Cerling et al., 2013]. More recently, Manthi et al. [2020] found Kanapoi $A u$. anamensis to have similar $\delta 13 \mathrm{C}$ values to extant "savanna" Pan populations. They inferred that the hominins at the Kanapoi $A u$. anamensis location were feeding on $\mathrm{C} 3$ foods such as fruit and leaves from trees within a grassy woodland/bushland/shrubland with a non-continuous canopy. Our understanding of the palaeoenvironment at Laetoli at the time of formation of the footprint trails and the date of the type specimen of $A u$. afarensis is still in flux, but Su and Harrison [2007, p. 303] summarize it as "a mosaic habitat comprising of open woodland, grassland and shrubland, as well as closed woodland along seasonal water courses." Eruptions of the Sadiman volcano, and the consequent ashfall, in which the Laetoli footprint trails were made, seem to have caused only short-term disruptions of this environment. Although Rift Valley hominin habitats have a distinctly different physical geography from the Witwatersrand craton, the palaeoenvironment at Laetoli at the time of the
Upper Laetoli beds and that of the Kanapoi Au. anamensis may not have been very different from that at either Sterkfontein in Member 2 times, except that watercourses were likely permanent and associated closed forest likely present at Sterkfontein. Neverthertheless, $A u$. anamensis, $A u$. afarensis and $A u$. prometheus were all likely effective in exploiting arboreal, open woodland forest and forest resources, but less effective in open grassland.

\section{Extinct Protohominin Locomotion}

Here, we discuss interpretations of likely locomotion in protohominins including Danuvius, Sahelanthropus, Orrorin and Ardipithecus, which have been mooted as illuminating the precursors of hominin bipedalism.

There is continued disagreement over whether the hominoid Danuvius was an arboreal biped at $11.62 \mathrm{Ma}$ [Williams et al., 2019; but see Böhme et al., 2020]. There is also continued disagreement over the bipedality of $\mathrm{Sa}$ helanthropus (approx. $7 \mathrm{Ma}$ ) due to the lack of postcranial evidence. A femur thought by some to belong to $\mathrm{Sa}$ helanthropus has been described by others as lacking any external or fracture-exposed evidence for bipedality [Macchiarelli et al., 2020]. MicroCT by Guy et al. [preprint, 2020] of this specimen revealed a prominent femoral calcar (robusticity proximomedial to the lesser trochanter), which is also present in the proximal femur of Orrorin [Kuperavage and Eckhardt, 2009; Kuperavage et al., 2018]. In humans, experimental cadaveric studies similarly make a strong link between the calcar femorale and stress distribution in the proximal femur of humans [Zhang et al., 2009]. Presence of a femoral calcar does not however imply that a fossil is a hominin, as some Gorilla specimens at least also exhibit a calcar femorale (e.g., KUPRI 1492 on the Kyoto University Digital Morphology Museum site [pers. commun. to R.H.C. from Adam Kuperavage]).

More broadly, we must consider body mass as a very significant influence on the ability to stabilize the body above branches during arboreal locomotion. The description [White et al., 2015] of the arboreal locomotor behaviour of Ar.w ramidus (4.4 Ma), as apparently dominated by "cautious climbing" and plantigrade quadrupedalism despite occasional orthograde bipedalism, is somewhat difficult to interpret in toto, while humans can and do display all of these in arboreal contexts [Venkataraman et al., 2014]. The high initial body weight estimate of $51 \mathrm{~kg}$ for ARA-VP-6/500 [Lovejoy et al., 2009a], as pointed out by Crompton et al. [2010], would be nearly twice the 
weight of males of the largest cercopithecine Mandrillus sphinx (approx. $32 \mathrm{~kg}$ [Smith and Jungers, 1997]) and much heavier than those of the largest colobines, Rhinopithecus roxellana and Nasalis larvatus (male masses approx. $20 \mathrm{~kg}$ [Smith and Jungers, 1997]). With no tail, and thick plantar tissue [Lovejoy et al., 2009a] which would have reduced gripping effectiveness, it is difficult to understand how it coped with inevitably high destabilizing torques in plantigrade quadrupedalism, or with (apparently) unsupported bipedalism in an arboreal context, as suggested by White et al. [2015]. It seems quite likely therefore that the lower estimate of about $32 \mathrm{~kg}$ by Grabowski et al. [2015] is more accurate. Apparently rejecting White's interpretations of Ardipithecus arboreal locomotion, Prang et al. [2021] attempted to resurrect a knuckle-walking/suspensory model of hominin origins based on morphometric analysis of the Ar. ramidus hand bones. It might be thought somewhat obtuse to model locomotion of the whole body entirely from one of the functionally most variable and least determinate parts of the body, and, although suspensory locomotion is evidenced in all living hominoids, including ourselves, knuckle-walking is not and appears to have been independently derived in Pan and Gorilla [Kivell and Schmitt, 2009].

It remains the case that at approximately $3.67 \mathrm{Ma}$, only $0.73 \mathrm{Ma}$ after the date of Ar. ramidus, Au. prometheus StW 573 was a capable upright terrestrial biped able to traverse over short to medium distances. Yet it continued to engage extensively in arboreal activity, likely using a mix of (sometimes) hand-assisted bipedality and quadrumanous climbing. Its lower limb was very similar to our own, as far as joint shape was concerned, although longbone length was primitively short, which may have limited endurance in terrestrial walking, and as noted above, the semicircular canals [Beaudet et al., 2019b] and joints in the atlas [Beaudet et al., 2020] appear to be better adapted for mobility in a three-dimensionally complex arboreal environment. Also, the effectiveness of blood perfusion of the brain, as witnessed by the small crosssection of the carotid foraminae of the atlas [Beaudet et al., 2020], does not appear to be adapted for extended activity in open country.

StW 573 may have engaged in some suspension, but then so do humans, as discussed below. There is no evidence whatsoever in the StW 573 hands of knuckle-walking, nor in those of $A u$. afarensis. Its upper limb, however, retained an ability greater than our own to use supports above shoulder level. Variability in Australopithecus postcrania is very high, but StW 573 falls within that range of variation in nearly all characteristics. Postcranial features seem to be built on proportions that are primitive for living great apes as a whole, not derived as those of Pan seem to be. If Pan and Homo separated between 4 and $8 \mathrm{Ma}$, as Wood and Grabowski [2015] conclude, that is very close to, or after, the dates for Sahelanthropus, Orrorin and possibly even Ar. ramidus, which all display some features at least of upright bipedalism.

\section{Biomechanical Performance Data for Extant Great Apes}

If we accept the argument of Böhme et al. [2019; but see Williams et al., 2019], some European late Miocene apes, such as Danuvius, did sometimes walk bipedally, with extended knees, in an arboreal context [as does Pongo today, see Thorpe et al., 2007]. However, Böhme et al. [2019] reject our "hand-assisted bipedalism" model [Thorpe et al., 2007; Crompton et al., 2010]. They erected their own new locomotor category for Danuvius, "extended limb clambering" on the grounds that lower limb forces in orang-utan bipedalism are insufficient to exert hip and knee forces of the scale that would require the bony buttressing they claim to have observed. They do not present evidence to support this assertion. Crompton et al. [2010] argued that as torques (tending to flex joints and destabilize the body above a supporting branch) will increase as the cube of linear dimensions, but muscle power to resist them only as the square of linear dimensions [Alexander, 2003]; orthogrady, permitting the hands to exert much larger balancing moments about the feet than in quadrupedal posture, is increasingly beneficial with increased size. Further, Johanssen et al. [2017] demonstrated that exposing human subjects to a movie of swaying branches while they stood on a branch-like bouncy springboard destabilized them as much as wearing a blindfold when on the same support. Light fingertip support significantly enhanced balance and reduced thigh muscle activity by up to a third. Thus, the origins of hominin bipedalism in arboreal bipedalism with extended joints may have been driven substantially by increased body size in apes.

It is evident from Heaton et al. [2019] that upper limb lengths were short in StW 573 compared to the living non-human great apes. This suggests less ability to embrace large supports with the upper limb and, particularly, shorter reach, which we hypothesize reduces the energetic efficiency of arboreal locomotion. Unusually, perhaps, an analogy to human performance capacities 
can be used to provide some test of this hypothesis. Halsey et al. [2017] measured the impact of variation in morphology and locomotor behaviour on the rate of oxygen consumption of 19 elite male parkour athletes as they repeatedly traversed an arboreal-like assault course of $103 \mathrm{~m}$ horizontal length, including arm swinging/brachiation. The course consisted of a range of generic gymnasium apparatus such as vaulting horses, raised blocks, high bars, wall bars, and areas filled with loose foam blocks to emulate the range of mechanical conditions present in an arboreal pathway, rather than the exact structure of the forest canopy. Thus, parts of the course incorporated support compliance, irregularity and discontinuity to reflect the conditions experienced during gap crossing between tree crowns. Others were rigid and predicated to reflect the phases between bouts of gap crossing when even large-bodied apes may walk into and out of the core of a tree along thick boughs. Halsey et al. [2017] found that familiarity with the course had a substantial effect on reducing energetic costs, but there was no evidence to suggest that the locomotor behaviour profile of each individual (or the combination of locomotor behaviours that they selected between first and last trials) influenced their ability to attenuate costs. We must, therefore, presume more subtle mechanical adjustments are being made to attenuate locomotor challenges. Importantly, athletes with longer arm spans and shorter legs were particularly able to achieve energetic economies. Thus, our hypothesis that shorter reach would reduce the efficiency of arboreal locomotion is confirmed for one hominin at least, namely $H$. sapiens. Therefore, based on this analogy, we conclude that the limb proportions of StW 573 would indeed likely have reduced her energetic efficiency in arboreal climbing compared to non-human great apes, but given her high humeral length, reach and thus efficiency would have been higher than in Homo, suggesting that StW 573 was under active selection to balance terrestrial and arboreal effectiveness.

Crompton et al. [2003] rejected both the knucklewalking quadrupedalism model [Gebo, 1992] and the vertical climbing model of Fleagle et al. [1981] for the origins of bipedality, on kinematic grounds, since both normally raised $P$. troglodytes and $P$. paniscus do not sustain voluntary bipedalism for more than a couple of seconds. They also do not attain hip and knee extension ranges close to those in human bipedal walking. Orang-utans, however, can sustain hip and knee extension ranges in voluntary bipedal walking very close to those that we sustain. Instead, they proposed arboreal orthograde scram- bling like that of orang-utans, including an element of hand-assisted bipedality, as the likely forerunner of bipedal walking.

With respect to the origins of orthogrady itself, we suggest that increased body weight, and thus increased lateral torques about the thorax tending to rotate the body around the branch, decreases stability [Crompton et al., 2010]. It is noteworthy that it is females, not males, which appear to be the most often arboreal in Mandrillus, Rhinopithecus and Nasalis [R.H.C., pers. observation]. Orthogrady, evident in hominoids from Morotopithecus (approx. 18-20 Ma) onwards, either avoids this issue by facilitating forelimb suspension or, in compressive orthogrady, by enabling the hands to exert much higher leverage about the feet by lateral reach branch contact at around shoulder height, than the destabilizing torques exerted by gravity about the feet. Monkeys appear to lack the thoracolumbar adaptations allowing sustained orthogrady seen in all apes.

Watson et al. [2009] investigated kinematics during load carrying in humans and zoo populations of common chimpanzees, bonobos, lowland gorillas and Bornean orang-utans and found that in quadrupedal locomotion load carriage led to a more upright trunk and a change in shoulder motion. These changes were exacerbated progressively in tripedal and bipedal gaits when carrying more awkward loads. Thus, load carrying may have contributed to erect truncal posture and changes in the shoulder.

Thus, we suggest that StW 573 was an effective arboreal biped and climber that had sacrificed some arboreal effectiveness in favour of enhanced energetic efficiency in walking medium distances on the ground. Her locomotor posture was competent upright bipedalism, whether on the ground or on branches, and she was able to stand upright without much muscular activity because of a "locking" or "screw-home" mechanism in the knee. Such a feature does not seem to have been present in $\mathrm{Ar}$. ramidus, suggesting that it was unlikely to have engaged extensively in terrestrial bipedalism. The two other early Australopithecus, Au. anamensis and Au. afarensis KSDVP-1/1 however probably shared a similar niche to StW 573 , since a locking mechanism is also present in the knee of Au. afarensis at least. Despite the claim of Böhme et al. [2019] that Danuvius had marked knee buttressing (but again see Williams et al. [2019]) which could not be accounted for by what they claim are small forces in orangutan-like bipedalism, the mean of vertical force peaks in orang-utan bipedalism measured by forceplate is actually not small compared to those in Homo: between 0.84 
[Payne, 2001] and 0.95 [Kimura, 1985] times body weight according to individual, versus 1.23 times body weight in H. sapiens [Kimura, 1985]. Neither do Böhme et al. [2019] consider the experimental evidence of Johannsen et al. [2017] who showed that light fingertip contacts (light touch) can dramatically stabilize bipedal walking on supports in simulated arboreal environments, reducing required hip muscle forces by some $30 \%$. In other words, orang-utan bipedalism is, like our own, compressive orthogrady [Thorpe and Crompton, 2007], where the superincumbent weight is borne by the legs. Thus, the creation of another locomotor category by Böhme et al. [2019] is most likely unwarranted. Hand-assisted bipedality is the appropriate descriptor for the locomotion that likely gave rise to hominin bipedality. Thorpe and Crompton's [2007] discussion of locomotion in orangutans was based on the standard descriptors in Hunt et al. [1996], and we endorse their plea that new locomotor categories should not be generated without due consideration, especially where a single fossil specimen, the locomotion of which cannot be observed, is under discussion.

\section{Virtual Models and Their Impact on the Origins of Bipedalism}

The locomotor anatomy of Pan is commonly regarded as derived with respect to the last common ancestor with Homo [Isler et al., 2006; Drapeau and Ward, 2007; White et al., 2015; Young et al., 2015]. Chimpanzees have a remarkably narrow range of intermembral indices. Isler et al. [2006] demonstrate that this narrow range optimizes swing symmetry between fore- and hindlimbs, which is a basis for effectiveness in terrestrial quadrupedal gait. The chimpanzee intermembral index is high, and it is suggestive that manuports used by chimpanzees as hammerstones in cracking Panda oleosa nuts in the Taï forest are carried no more than 10-15 m [Profitt et al., 2018]. Inverse dynamic modelling by Wang and Crompton [2004a, b] based on limb proportions showed that chimpanzees cannot carry loads without incurring dramatically higher mechanical energy costs. AL-288-1 would have incurred considerably smaller cost increases but primarily when walking upright, and KNM-WT 15000 would have been able to shoulder-carry loads of $10-15 \%$ of body mass with no greater mechanical cost than AL-288-1 would incur walking upright but unloaded.

Given the proportions of StW 573, with a high intermembral index, outside the human range and higher than the index of KNM-WT 15000, we may hypothesize that StW 573 would not perform as well in load carrying as would KNM-WT 15000. However, we may further hypothesize that the somewhat longer legs and shorter arms of StW 573 would have given increased distancespecific effectiveness in unloaded bipedalism, compared to non-human great apes, but not when load carrying.

Feix et al. [2015] use an interesting modelling approach to assess the relative importance of thumb length and joint mobility in high-precision manipulation and find that both are prerequisites for the manipulation potential required for stone tool manufacture: both appear to have been present in Au. afarensis, but despite the long thumb, the apical ridge on the trapezium of StW 573 thus suggests that prehension was less important to this individual at least than stable grasps on arboreal supports, There is no evidence of tool manufacture in Sterkfontein Member 2. Performance assessments of manipulative skills by humans, gorillas and orang-utans [Bardo et al., 2017] interestingly rated gorillas higher than orangutans, which they suggest may reflect the greater terrestriality of the former. Bardo et al. [2018] went on to use modelling approaches to assess biomechanical potential for tool-related behaviours, and again orang-utans perform poorly, requiring higher muscle forces for a similar range of motion. The hand of Au. sediba however would have had the potential for stone tool use and perhaps manufacture, and these contributions together might suggest that prehensive capability had become more important to these individuals than stable grasping of larger vines and branches, consistent with the suggestion of Bardo et al. [2017].

Lowland gorillas have the most human-like foot proportions among the great apes [Schultz, 1963], having, for example, a long tarsus and short lateral phalanges [Schultz, 1963]: the phalanges of the third digit are about $33 \%$ of foot length versus $43 \%$ in Pongo and 35\% in P. troglodytes. In a static analysis, gorillas have a power arm to load arm ratio equal to that of humans, better than either chimpanzee or orang-utan, albeit at the cost of large normal forces at the ankle [Wang and Crompton, 2004b]. Further, Wang et al. [2014] found that in simulations of human-like bipedal walking, it is gorillas which most resembled humans in terms of mean joint force and mean joint torque in the joints of the foot. As they do perform both hand-assisted bipedality and some terrestrial bipedality in the wild, gorillas seem to be the most useful living comparator among the African apes [reviewed in Crompton, 2016]. Together with Goh 
et al. [2017, 2019], these data strongly suggest that a postcranially relatively gorilla-like last common ancestor for humans and chimpanzees is most likely. Indeed, this idea is not new, being suggested by Elliot Smith in 1924. However, there remains the question of what ecological advantage accrues to gorillas from their own locomotor configuration that does not accrue to hominins in the same habitat. This advantage might revolve round gorillas' greater ability to climb large cross-section tree trunks, for which modern humans require technological aids. Forwards dynamic modelling of musculoskeletal performance [Sellers et al., 2005, 2010] in vertical climbing in lowland gorillas, and in StW 573 once the trunk is reconstructed, should prove highly informative. It should, however, be combined with field studies of indigenous populations of humans living in sympatry with western lowland gorillas, most likely in the Congo basin, to differentiate arboreal zone access capabilities in humans and gorillas.

\section{Conclusions}

Following Wainwright's [1991] formulation of ecomorphology, we suggest that the potential niche of StW 573 was exploitation of both arboreal and terrestrial contexts, facilitated by locomotor plasticity. Under the assumption of such plasticity, arboreality probably remains part of the potential niche of $H$. sapiens. Our species can and does engage in cautious climbing and even plantigrady, as well as orthograde, and often, just like StW 573, hand-assisted bipedality in arboreal contexts. These remain part of our potential niche, expressed in some living populations [Kraft et al., 2014].

It seems likely that StW 573 was, in her realized niche in the Blaaubank valley environment, an effective arboreal biped and climber that had sacrificed some arboreal effectiveness in favour of enhanced energetic efficiency in walking medium distances on the ground. Her habitual locomotor posture was upright bipedalism, whether on the ground or on branches, and she was able to stand upright without much muscular activity because of a "locking" or "screw-home" mechanism in the knee which does not seem to have been present in Ar. ramidus. A niche similar to that of StW 573 was probably shared by $A u$. anamensis [Bobe et al., 2020] and KSD-VP-1/1 Au. afarensis [Su, 2016]. Thus, Pan can no longer be seen as the most suitable locomotor comparator for early hominins, while Pongo remains very largely but not exclusively arboreal. Despite an earlier separation date from Hominini than that of Panini, Gorilla species are probably more informative as an extant species for locomotor comparisons.

Regarding an australopith bauplan, comparisons with other available australopith skeletal materials suggest broadly similar adaptations and ecomorphology, towards arboreal and terrestrial exploitation of woodland, and terrestrial exploitation of grassland in the immediate vicinity within the constraints of palaeoenvironmental differences. Wood and Boyle [2016] noted that taxonomic diversity is high in hominins and protohominins from 4 $\mathrm{Ma}$, but this diversity was assessed primarily from considerations of cranial morphology. However, there are indications that some, but by no means all, later Australopithecus such as $A u$. sediba were more terrestrial than early australopiths. Finally, and most importantly, since the great apes (including humans) have responded to climate instability specifically by retaining and enhancing plasticity [Neufuss et al., 2014], we should expect variability in great ape evolution and base our interpretation of fossil taxa on that expectation.

\section{Acknowledgements}

R.H.C. thanks Matt Lotter, Matt Caruana and Kristiaan D'Aout for photographic assistance. Figure 1a from Clarke [2019] was reused with permission from Elsevier (license 4942050211741). Figure $1 \mathrm{~b}$ is by courtesy of Paul Myburgh. We thank Brigitte Senut and referee 2 for helpful suggestions, and Anna Nekaris for her skills in spotting infelicities in our text.

\section{Conflict of Interest Statement}

The authors have no competing interests to declare.

\section{Funding Sources}

This paper was written under an Emeritus Fellowship EM2017-010 from the Leverhulme Trust to R.H.C., whose wider research in hominin biology has been primarily funded by kind support from the UK Natural Environment Research Foundation and the Leverhulme Trust over many years. Major funding for the Sterkfontein excavations and microCT scanning work has been supported by National Research Foundation grants to K.K. (No. 82591 and 82611) and to Dominic Stratford (No. 98808) and by the Palaeontological Scientific Trust (PAST), without whose support this research would not have been able to continue. We particularly thank Andrea Leenen and Rob Blumenschine for their help in securing major corporate funding, including sustained support from Standard Bank and J.P. Morgan. 


\section{Author Contributions}

Crompton, McClymont, Elton and Thorpe conceived and wrote most of the text; Sellers, Pataky and Goh contributed ideas on in silico experimentation; Heaton, Pickering, Carlson, Jashashvili, Beaudet and Bruxelles commented on sections within their particular expertise. Kuman helped tremendously with editing and provision of images. Clarke led the excavation and preparation team over the two decades since discovery of the first foot bones and provided discussion and comments on the text.

\section{Dedication}

R.H.C. and J.M.C. dedicate their contribution to the memory of their close friend and colleague, Russ Savage.

\section{References}

Aiello LC, Dean C (1993). Human Evolutionary Anatomy. London, Academic Press.

Alba DM, Moyà-Solà S, Köhler M (2003). Morphological affinities of the Australopithecus afarensis hand on the basis of manual proportions and relative thumb length. Journal of Human Evolution 44: 225-254.

Alemseged Z, Wynn JG, Kimbel WH, Reed D, Geraads D, Bobe R (2005). A new hominin from the Basal Member of the Hadar Formation, Dikika, and its geological context. Journal of Human Evolution 49: 499-514.

Alexander R McN (2003). Principles of Animal Locomotion. Princeton, Princeton University Press.

Andrews P (2020). Last common ancestor of apes and humans: morphology and environment. Folia Primatologica 91: 122-148.

Asfaw B, White T, Lovejoy O, Latimer B, Simpson S, Suwa G (1999). Australopithecus garhi: a new species of early hominid from Ethiopia. Science 284: 629-635.

Bamford M (1999). Pliocene fossil woods from an early hominid cave deposit, Sterkfontein, South Africa. South African Journal of Science 95: 231-237.

Bardo A, Cornette R, Borel A, Pouydebat E (2017). Manual function and performance in humans, gorillas and orangutans during the same tool use task. American Journal of Physical Anthropology 164: 821-836.

Bardo A, Vigouroux L, Kivell TL, Pouydebat E (2018). The impact of hand proportions on tool grip abilities in humans, great apes and fossil hominins: a biomechanical analysis using musculoskeletal simulation Journal of Human Evolution 125: 106-121.

Beaudet A, Clarke RJ, de Jager EJ, Bruxelles L, Carlson KJ, Crompton R, et al (2019a). The endocast of StW 573 ("Little Foot") and hominin brain evolution. Journal of Human Evolution 126: 112-123.

Beaudet A, Clarke RJ, Bruxelles L, Carlson KJ, Crompton R, de Beer F, et al (2019b). The bony labyrinth of StW 573 ("Little Foot"): implications for early hominin evolution and paleobiology. Journal of Human Evolution 127: $67-80$.
Beaudet A, Clarke RJ, Carlson KJ, Heaton JL, Carlson KJ, Crompton RH, et al (2020). The atlas of StW 573 and the late emergence of human-like head mobility and brain metabolism. Nature Scientific Reports 10(4285): 1-13.

Beaudet A, Atwood R, Kockelmann W, Fernandez V. Connolley T, Trong N, et al (2021). Preliminary paleohistological observations of the StW 573 ("Little Foot") skull. eLife 10: e64804.

Berger LR, De Ruiter DJ, Churchill SE, Schmid P, Carlson KJ, Dirks PH, et al (2010). Australopithecus sediba: a new species of Homo-like Australopithecus from South Africa. Science 328: 195-204.

Berger LR, Hawks J (2019). Australopithecus prometheus is a nomen nudum. American Journal of Physical Anthropology 168: 383-387.

Bobe R, Manthi FK, Ward CV, Plavcan JM, Carvalho S (2020). The ecology of Australopithecus anamensis in the early Pliocene of Kanapoi, Kenya. Journal of Human Evolution 140: 102717.

Bock WJ, von Wahlert G (1965). Adaptation and the form-function complex. Evolution 19: 269-299.

Böhme M, Spassov N, Fuss J, Tröscher A, Deane AS, Prieto J, et al (2019). A new Miocene ape and locomotion in the ancestor of great apes and humans. Nature 575: 489-491.

Böhme M, Spassov N, DeSilva JM, et al (2020). Reply to: reevaluating bipedalism in Danuvius. Nature 586: E4-E5.

Broom R, Robinson JT, Schepers GWH (1950). Sterkfontein ape-man, Plesianthropus. Transvaal Museum Memoir No. 4. Pretoria, Transvaal Museum.

Bruxelles L, Stratford DJ, Maire R, Pickering TR, Heaton J, Beaudet A (2019). A multiscale stratigraphic investigation of the context of StW 573 "Little Foot" and Member 2, Sterkfontein Caves, South Africa. Journal of $\mathrm{Hu}$ man Evolution 133: 78-98.

Carlson KJ, Zipfel B, Jungers WL (2020). Tibia and fibula. In Hominin Postcranial Remains from Sterkfontein, South Africa, 1936-1995 (Zipfel B, Richmond BG, Ward CV, eds.), pp 220-250. Oxford, Oxford University Press.
Carlson KJ, Green DJ, Jashashvili T, Pickering TR, Heaton JL, Beaudet A et al (2021). The pectoral girdle of StW 573 ("Little Foot") and its implications for hominin evolution. Journal of Human Evolution DOI: 10.1016/j. jhevol.2021.103008.

Cerling TE, Manthi FK, Mbua EN, Leakey LN, Leakey MG, Leakey RE, et al (2013). Stable isotope-based diet reconstructions of Turkana Basin hominins. Proceedings of the National Academy of Sciences 110: 10501-10506.

Chirchir H (2019). Trabecular bone fraction variation in modern humans, fossil hominins and other primates. The Anatomical Record 302 . 288-305.

Churchill SE, Holliday TW, Carlson KJ, Jashashvili T, Macias ME, Mathews S, et al (2013). The upper limb of Australopithecus sediba. Science 340: 1233477.

Clarke RJ (1988). A new Australopithecus cranium from Sterkfontein and its bearing on the ancestry of Paranthropus. In: Evolutionary History of the "Robust" Australopithecines (Grine F, ed.), pp 285-292. New York, Aldine de Gruyter.

Clarke RJ (1994). Advances in understanding the craniofacial anatomy of South African early hominids. In Integrative Paths to the Past: Essays in Honor of F. Clark Howell (Corruccini RS, Ciochon RL, eds.), pp 205-222. Englewood Cliffs, Prentice-Hall

Clarke RJ (1998). Discovery of complete arm and hand of the 3.3 million-year-old Australopithecus skeleton from Sterkfontein. South African Journal of Science 95: 477-480.

Clarke RJ (2002). Newly revealed information on the Sterkfontein Member 2. Australopithecus skeleton: news \& views. South African Journal of Science 98: 523-526.

Clarke RJ (2013). Australopithecus from Sterkfontein Caves, South Africa. In The Paleobiology of Australopithecus (Reed KE, Fleagle JG, Leakey REF, eds.), pp 105-123. Dordrecht, Springer.

Clarke RJ (2019a). Excavation, reconstruction and taphonomy of the StW 573 Australopithecus skeleton from Sterkfontein Caves, South Africa. Journal of Human Evolution 127: 41-53.

Clarke RJ (2019b). Australopithecus prometheus was validly named on MLD 1. American Journal of Physical Anthropology 170: 479-481. 
Clarke RJ, Kuman K (2019). The skull of StW 573, a ca $3.67 \mathrm{Ma}$ Australopithecus skeleton from Sterkfontein Caves, South Africa. Journal of Human Evolution 134: 102634.

Clarke RJ, Tobias PV (1995). Sterkfontein Member 2 foot bones of the oldest South African hominid. Science 269: 521-524.

Claxton AG, Hammond AS, Romano J, Oleinik E, DeSilva J (2016). Virtual reconstruction of the Australopithecus africanus pelvis Sts 65 with implications for obstetrics and locomotion. Journal of Human Evolution 99: 10-24.

Clemente CD (1985). Shoulder joint and muscles of the shoulder. In Gray's Anatomy (Gray H, ed.), 30th American edition, pp 370-525. Baltimore, Williams \& Wilkins.

Conroy GC (1976). Primate Postcranial Remains from the Oligocene of Egypt. Paris: PascalFrancis.

Crompton RH (2016). The hominins: a very conservative tribe? Last common ancestors, plasticity and ecomorphology in Hominidae. Or, what's in a name? Journal of Anatomy 228: 686-699.

Crompton RH, Li Y, Thorpe SK, Wang WJ, Savage R. Payne R, Carey TC, Aerts P, Van Elsacker L, Hofstetter A, Gunther MM, D'Aout $\mathrm{K}$, DeClerq D (2003). The biomechanical evolution of erect bipedality. Courier Forschungsinstitut Senckenberg 243: 115-126.

Crompton RH, McClymont J, Thorpe S, Sellers W, Heaton J, Pickering TR, Pataky T, Stratford D, Carlson K, Jashashvili T, Beaudet A, Bruxelles L, Goh C, Kuman K, Clarke R (2020). Functional anatomy, biomechanical performance capabilities and potential niche of StW 573: an Australopithecus skeleton (circa 3.67 Ma) from Sterkfontein Member 2, and its significance for the last common ancestor of the African apes and for hominin origins (Preprint). BioxRiv DOI: https: //doi. org/10.1101/481556.

Crompton RH, Sellers WI, Thorpe SKS (2010). Arboreality, terrestriality and bipedalism. Philosophical Transactions of the Royal Society Series B 365: 3301-3315.

Dainton M (2001). Did our ancestors knucklewalk? Nature 410: 324-325.

Dainton M, Macho GA (1999). Did knuckle walking evolve twice? Journal of Human Evolution 36: 171-194.

Darwin C (1859). On the Origin of Species. London, John Murray.

Day MH (1969). Femoral fragment of a robust Australopithecine from Olduvai Gorge, Tanzania. Nature 221: 230-233.

Deloison Y (2003). Fossil footbones anatomy from South Africa between 2.4 and 3.5 My old (in French). Biometrie Humaine et Anthropologie 21: 189-230.

Deloison Y (2004). A new hypothesis on the origin of hominoid locomotion. In From Biped to Strider (Meldrum DJ, Hilton CE, eds.), pp 35-48. Boston, Springer.

DeSilva JM (2009). Functional morphology of the ankle and the likelihood of climbing in early hominins. Proceedings of the National Academy of Sciences of the USA 106: 6567-6572.
DeSilva JM, Holt KG, Churchill SE, Carlson, KJ, Walker CS, Zipfel B, et al (2013). The lower limb and mechanics of walking in Australopithecus sediba. Science 340: 1232999.

Dobzhansky T (1973). Nothing in biology makes sense except in the light of evolution. American Biology Teacher 35: 125-129.

Drapeau MSM (2008). Articular morphology of the proximal ulna in extant and fossil hominoids and hominins. Journal of Human Evolution 55: 86-102.

Drapeau MSM, Ward CV, Kimbel WH, Johanson DC, Rak Y (2005). Associated cranial and forelimb remains attributed to Australopithecus afarensis from Hadar, Ethiopia. Journal of Human Evolution 48: 593-642.

Drapeau MSM, Ward CV (2007). Forelimb segment length proportions in extant hominoids and Australopithecus afarensis. American Journal of Physical Anthropology 132: 327343.

Dye SF (1987). An evolutionary perspective of the knee. The Journal of Bone and Joint Surgery (American Volume) 69: 976-983.

Elliot Smith G (1924). The Evolution of Man. Essays. Oxford, Oxford University Press.

Elton S (2007). Environmental correlates of the cercopithecoid radiations. Folia Primatologica 78: 344-364

Elton S (2012). Impacts of environmental change and community ecology on the composition and diversity of the southern African monkey fauna from the Plio-Pleistocene to the present. In African Genesis. Perspectives on Hominin Evolution (Reynolds SC, Gallagher A, eds.), pp 471-486. Cambridge, Cambridge University Press.

Elton S, Jansson A-U, Meloro C, Louys J, Plummers T, Bishop LC (2016). Exploring morphological generality in the Old World monkey postcranium using an ecomorphological framework. Journal of Anatomy 228: 534560.

Feix T, Kivell TL, Pouydebat E, Dollar AM (2015). Estimating thumb-index finger precision grip and manipulation potential in extant and fossil primates. Journal of the Royal Society Interface 12: 20150176.

Fleagle JG, Stern JT, Jungers WL, Susman RL (1981). Climbing, a biomechanical link with brachiation and with bipedalism. Symposia of the Zoological Society of London 48: 359-375.

Fornai C, Krenn VA, Mitteroeker P, Webb NM (2021). Sacrum morphology supports taxonomic heterogeneity of "Australopithecus africanus" at Sterkfontein Member 4. Nature Communications Biology. htpps: //doi. org/10.10138/s42003-021-01850-7.

Galik K, Senut B, Pickford M, Gommery D, Treil J, Kuperavage AJ, Eckhardt RB (2004). External and internal morphology of the BAR 1002 '00 Orrorin tugenensis femur. Science 305: 1450-1453.

Gebo DL (1992). Plantigrady and foot adaptation in African apes - implications for hominid origins. American Journal of Physical Anthropology 89: 29-58.
Georgiou L, Dunmore CJ, Bardo A, Buck LT, Hublin J-J, Pahr DH, et al (2020). Evidence for habitual climbing in a Pleistocene hominin in South Africa. Proceedings of the National Academy of Sciences of the USA (Latest Articles) 1914481117: 1-8.

Glickel SZ, Baron OA, Eaton RG (1999) Dislocations and ligament injuries in the digits. In Green's Operative Hand Surgery (Green, DP, Hotchkiss M, Pederson WC, eds.), 4th ed., Vol 1, pp 772-808. Philadelphia, Churchill Livingstone.

Goh C, Blanchard ML, Crompton RH, Gunther MM, Macaulay S, Bates KT (2017). A 3D musculoskeletal model of the western lowland gorilla hind limb: moment arms and torque of the hip, knee and ankle. Journal of Anatomy 231: 568-584.

Goh C, Blanchard ML, Crompton RH, Gunther MM, Macaulay S, Bates KT (2019). A threedimensional musculoskeletal model of the western lowland gorilla foot: examining muscle torques and function. Folia Primatologica 90: 470-493.

Gommery D, Senut B (2005). La phalange distale du pouce d'Orrorin tugenensis, Miocène supérieur des Tugen Hills, Kenya. Geobios 39: 372-384.

Grabowski M, Hatala KG, Jungers WL, Richmond BG (2015). Body mass estimates of hominin fossils and the evolution of human body size. Journal of Human Evolution 85: 75-93.

Granger DE, Gibbon RJ, Kuman K, Clarke RJ, Bruxelles L, et al (2015). New cosmogenic burial ages for Sterkfontein Member 2 Australopithecus and Member 5 Oldowan. Nature 522: 85-88.

Grine FE, Susman RL (1991). Radius of Paranthropus robustus from member 1, Swartkrans formation, South Africa. American Journal of Physical Anthropology 84(3): 229-248.Guy F, Daver G, Mackaye HT, Likius A, Boisserie J-R, Moussa A, et al (2020). Postcranial evidence of late Miocene hominin bipedalism in Chad (preprint). Research Square. https://doi. org/10.21203/rs.3.rs-69453/v1

Haeusler M, Schmid P (1995). Comparison of the pelves of Sts 14 and Al-288-1: implications for birth and sexual dimorphism in Australopithecines. Journal of Human Evolution 29: 363-383.

Haile-Selassie Y, Latimer BM, Alene M, Deino AL, Gibert L, Melillo SM, et al (2010). An early Australopithecus afarensis postcranium from Woranso-Mille, Ethiopia. Proceedings of the National Academy of Sciences of the USA 107: 12121-12126.

Halsey LG, Coward SRL, Crompton RH, Thorpe SKS (2017). Practice makes perfect: performance optimisation in "arboreal" parkour athletes illuminates the evolutionary ecology of great ape anatomy. Journal of Human Evolution 103: 45-52.

Harrison T (1989). A reassessment of the phylogenetic relationships of Oreopithecus bambolii. Journal of Human Evolution 15: 541583. 
Heaton JL, Pickering TR, Beaudet A, Clarke RJ, Bruxelles L, Carlson KJ, et al (2019). The long limb bones of the StW 573 Australopithecus skeleton from Sterkfontein Member 2: descriptions and proportions. Journal of Human Evolution 133: 167-197.

Heile AJ, Pickering TR, Heaton JL, Clarke RJ (2018). Bilateral asymmetry of the forearm bones as possible evidence of antemortem trauma in the StW 573 Australopithecus skeleton from Sterkfontein Member 2 (South Africa)(preprint). bioRxiv DOI: 10.1101/486076.

Heinrich RE, Rose MD, Leakey RE, Walker AC (1993). Hominid radius from the middle Pliocene of Lake Turkana, Kenya. American Journal of Physical Anthropology 92: 139-148.

Hens SM, Konigsberg LW, Jungers WL (2000). Estimating stature in fossil hominids: which regression model and reference sample to use? Journal of Human Evolution 38: 767-784.

Hill A, Ward S (1988). Origin of the Hominidae: the record of African large hominoid evolution between $14 \mathrm{My}$ and $4 \mathrm{My}$. Yearbook of Physical Anthropology 31: 49-83.

Holowka NB, O'Neill MC, Thompson NE, Demes B (2017). Chimpanzee and human midfoot motion during bipedal walking and the evolution of the longitudinal arch of the foot. Journal of Human Evolution 104: 23-31.

Hooton EA (1946). Up from the Ape. New York, Macmillan.

Hunt KD (1991). Mechanical implications of chimpanzee positional behavior. American Journal of Physical Anthropology 86: 521-536.

Hunt KD (1994). The evolution of human bipedality: ecology and functional morphology. Journal of Human Evolution 26: 183-202.

Hunt KD, Cant JGH, Gebo DL, Rose MD, Walker SE, Youlatos D (1996). Standardised descriptions of primate locomotor and postural modes. Primates 37: 363-387.

Isler K, Payne RC, Günther MM, Thorpe SK, Li Y, Savage R, et al (2006). Inertial properties of hominoid limb segments. Journal of Anatomy 209: 201-218.

Jashashvili T, Tocheri MT, Carlson KJ, Clarke RJ (2020). Metatarsals and pedal phalanges. In Hominin Postcranial Remains from Sterkfontein, South Africa, 1936-1995 (Zipfel B, Richmond BR, Ward CV, eds.), pp 262-288. Oxford, Oxford University Press.

Johannsen L, Coward SRL, Martin GR, Wing AM, van Casteren A, Sellers WI, et al (2017). Human bipedal instability in tree canopy environments is reduced by "light touch" fingertip support. Nature Scientific Reports 7: 1135.

Johanson DC, Lovejoy CO, Kimbel WH, White TD, Ward SC, Bush ME, et al (1982). Morphology of the Pliocene partial hominid skeleton (AL 288-1) from the Hadar formation, Ethiopia. American Journal of Physical Anthropology 57: 403-451.

Keith A (1934). The Construction of Man's Family Tree. London, Watts.
Kimura T (1985). Bipedal and quadrupedal walking of primates: comparative dynamics. In Primate Morphophysiology, Locomotor Analyses and Human Bipedalism (Kondo S, ed.), pp 81-104. Tokyo, University of Tokyo Press.

Kivell TL (2016). A review of trabecular bone functional adaptation: what have we learned from trabecular analyses in extant hominoids and what can we apply to fossils? Journal of Anatomy 228: 569-594.

Kivell TL, Schmitt D (2009). Independent evolution of knuckle-walking in African apes shows that humans did not evolve from a knuckle-walking ancestor. Proceedings of the National Academy of Sciences of the USA 106: 14241-14246.

Koyabu DB, Endo H (2010). Craniodental mechanics and diet in Asian colobines: morphological evidence of mature seed predation and sclerocarpy. American Journal of Physical Anthropology 142: 137-148.

Kozma EE, Webb NM, Harcourt-Smith WE, Raichlen DA, D'Août K, Brown MH, Pontzer $H$ (2018). Hip extensor mechanics and the evolution of walking and climbing capabilities in humans, apes, and fossil hominins. Proceedings of the National Academy of Sciences 115: 4134-4139.

Kraft TS, Venkataraman VV, Dominy NJ (2014). A natural history of human tree climbing. Journal of Human Evolution 71: 105-118.

Kuperavage AJ, Eckhard RB (2009). Biomechanical inferences about the origins of bipedal locomotion from ancient African femora. Journal of Engineering Mechanics 135: 474-483.

Kuperavage A, Pokrajac D, Chavanaves S, Eckhard RB (2018). Earliest known Hominin calcar femorale in Orrorin tugenensis provides further internal anatomical evidence for origin of human bipedal locomotion. The Anatomical Record 301: 1834-1839.

Lamarck JB (1809). Philosophie zoologique, ou Exposition des considérations relatives à l'histoire naturelle des animaux Paris (transl. Elliot, 1914). London, Macmillan.

Larson SG (2007). Evolutionary transformation of the hominin shoulder. Evolutionary Anthropology 16: 172-187.

Larson SG (2015). Humeral torsion and throwing proficiency in early human evolution. Journal of Human Evolution 85: 198-205.

Latash ML, Scholz JP, Schöner G (2002). Motor control strategies revealed in the structure of motor variability. Exercise and Sport Sciences Reviews 30: 26-31.

Lockwood C, Tobias PV (2002). Morphology and affinities of new hominin cranial remains from Member 4 of the Sterkfontein Formation, Gauteng Province, South Africa. Journal of Human Evolution 42: 389-450.

Lovejoy CO (2007). The natural history of human gait and posture. 3. The knee. Gait \& Posture 25: $325-341$.
Lovejoy CO, Latimer BM, Spurlock L, Haile-Selassie Y (2016). The pelvic girdle and limb bones of KSD/VP/1-1. Ethiopia. In The Postcranial Anatomy of Australopithecus afarensis: New Insights from KSD-VP-1/1 (Haile-Selassie Y, Su DF, eds.), pp 155-177. Dordrecht, Springer.

Lovejoy CO, Meindl RS, Ohman JC, Heiple KG, White TD (2002). The Maka femur and its bearing on the antiquity of human walking: applying contemporary concepts of morphogenesis to the human fossil record. American Journal of Physical Anthropology 119: 97-133.

Lovejoy CO, Simpson SW, White TD, Asfaw B, Suwa G (2009a). Careful climbing in the Miocene: the forelimbs of Ardipithecus ramidus and humans are primitive. Science 326(5949): 70-70e8.

Lovejoy CO, Suwa G, Simpson SW, Matternes JH, White TD, Asfaw B (2009b). The Great Divides: Ardipithecus ramidus reveals the postcrania of our last common ancestors with African apes. Science 326: 100-1006.

Macho GA, Fornai C, Tardieu C, Hopley P, Haeusler M, Toussaint M (2020). The partial skeleton StW 431 from Sterkfontein - is it time to rethink the Plio-Pleistocene hominin diversity in South Africa? Journal of Anthropological Sciences 98: 73-88.

Macchiarelli R, Bergeret-Medina A, Marchi, D, Wood B (2020). Nature and relationships of Sahelanthropus tchadensis. Journal of Human Evolution 149: 102898.

Manthi FK, Cerling TE, Chritz KL, Blumenthal SA (2020). Diets of mammalian fossil fauna from Kanapoi, northwestern Kenya. Journal of Human Evolution 140: 102338.

Marchi D (2015). Using the morphology of the hominoid distal fibula to interpret arboreality in Australopithecus afarensis. Journal of $\mathrm{Hu}$ man Evolution 85: 136-148.

Marchi D, Walker CS, Wei P, Holliday TW, Churchill SE, Berger LR, DeSilva JM (2017). The thigh and leg of Homo naledi. Journal of Human Evolution 104: 174-204.

Masao FT, Ichumbaki EB, Cherin M, Barili A, Boschian G, Iurino DA, et al (2016). New footprints from Laetoli (Tanzania) provide evidence for marked body size variation in early hominins. eLife 5: e19568.

McClymont J, Crompton RH (2020). Repetition without repetition: a comparison of the Laetoli G1, Ileret, Namibian Holocene and modern human footprints using pedobarographic statistical parametric mapping. In Reading Prehistoric Human Tracks (Pastoors A, Lenssen-Erz T, eds.), pp 41-65. Dordrecht, Springer.

McHenry HM, Brown CC (2008). Side steps: the erratic pattern of hominin postcranial change through time. Journal of Human Evolution 55: 639-651.

Melillo SM, Gunz P, Coqueugniot H, Reske S, Hublin JJ (2019). Structural effects of variation in the human clavicle. American Journal of Physical Anthropology 168: 687-704. 
Moya-Sola S, Kohler M (1996). A Dryopithecus skeleton and the origins of great-ape locomotion. Nature 379: 158-159.

Napier JR, Davis PR (1959). The fore-limb skeleton and associated remains of Proconsul africanus. Fossil Mammals of Africa 16: 1-69.

Neufuss J, Hesse B, Thorpe SKS, Vereecke EE, D’Août K, Fischer MS, et al (2014). Fibre type composition in the lumbar perivertebral muscles of primates: implications for the evolution of orthogrady in hominoids. Journal of Anatomy 224: 113-131.

Organ JM, Ward CV (2006). Contours of the lateral tibial condyle with implications for Australopithecus. Journal of Human Evolution 51 113-127.

O’Regan HJ, Reynolds SC (2009). An ecological reassessment of the southern African carnivore guild: a case study from Member 4, Sterkfontein, South Africa. Journal of Human Evolution 57(3): 212-222.

Partridge TC, Granger DE, Caffee MW, Clarke RJ (2003). Lower Pliocene hominid remains from Sterkfontein. Science 300(5619): 607612.

Patel BA, Jashashvili T, Bui SH, Carlson KJ, Griffin NL, Wallace IJ, Orr CM, Susman RL (2018). Inter-ray variation in metatarsal strength properties in humans and African apes: implications for inferring bipedal biomechanics in the Olduvai Hominid 8 foot Journal of Human Evolution 121: 147-165.

Payne RC (2001). Musculoskeletal Adaptations for Climbing in Hominoids and Their Role as Exaptions for the Acquisition of Bipedalism. PhD dissertation, University of Liverpool.

Pickford M, Senut B, Gommery D, Treil J (2002). Concise review paper: Bipedalism in Orrorin tugenensis revealed by its femora. Comptes Rendues en Palevolution 1: 191-203.

Pickering TR, Clarke RJ, Heaton JL (2004). The context of StW 573, an early hominid skull and skeleton from Sterkfontein Member 2: taphonomy and paleoenvironment. Journal of Human Evolution 46: 277-295.

Pickering TR, Heaton JL, Clarke RJ, Stratford D (2019). Hominin vertebrae and upper limb bone fossils from Sterkfontein Caves, South Africa (1998-2003 excavations). American Journal of Physical Anthropology 168: 459480.

Prang TC, Ramirez K, Grabowsk M, Williams SA (2021). Ardipithecus hand provides evidence that humans and chimpanzees evolved from an ancestor with suspensory adaptations. Science Advances 7: eafb2474.

Profitt T, Haslam M, Merader J, Boesch C, Luncz L (2018). Revisiting Panda 100: reanalysis of the first archaeological chimpanzee nut cracking lithic assemblage and its relevance to understanding the emergence of hominin technology. Proceedings of the 8th Annual Meeting of the European Society for the Study of Human Evolution, Faro, p 157.

Pontzer H (2017). Economy and endurance in human evolution. Current Biology 27(12): R613-R621.
Rein TR (2020). A comparative analysis of femoral biomechanical neck length in primates. The Anatomical Record 24377: 1-14.

Rein TR, Harrison T, Carlson KJ, Harvati K (2017). Adaptation to suspensory locomotion in Australopithecus sediba. Journal of Human Evolution 104: 1-12.

Reno PL, McCollum MA, Lovejoy CO, Meindl RS (2000) Adaptationism and the anthropoid postcranium: selection does not govern the length of the radial neck. Journal of Morphology 246: 59-67.

Riga A, Mori T, Pickering TR, Moggi-Cecchi J, Menter CG (2018). Ages-at-death distribution of the early Pleistocene hominin fossil assemblage from Drimolen (South Africa). American Journal of Physical Anthropology DOI: 10.1002/ajpa.23771.

Richmond BG, Begun DR, Strait DS (2001). Origin of human bipedalism: the knuckle-walking hypothesis revisited. Yearbook of Physical Anthropology 44: 70-105.

Roach NT, Richmond BG (2015). Clavicle length, throwing performance and the reconstruction of the Homo erectus shoulder. Journal of Human Evolution 80: 107-113.

Rose MD (1989). New postcranial specimens of catarrhines from the Middle Miocene Chinji Formation, Pakistan: descriptions and a discussion of proximal humeral functional morphology in anthropoids. Journal of Human Evolution 18: 131-162.

Ruff CB, Hayes WC (1983a). Cross-sectional geometry of Pecos pueblo femora and tibiae - a biomechanical investigation. I. Method and general patterns of variation. American Journal of Physical Anthropology 60: 359-381.

Ruff CB, Hayes WC (1983b). Cross-sectional geometry of Pecos pueblo femora and tibiae - a biomechanical investigation. II. Sex, age, and side differences. American Journal of Physical Anthropology 60: 383-400.

Ruff CB, Niskanen M (2018). Introduction to special issue: body mass estimation - methodological issues and fossil applications. Journal of Human Evolution 115: 1.

Schultz AH (1930). The skeleton of the trunk and limbs of higher primates. Human Biology 2(3): 303-438.

Schultz AH (1937). Proportions, variability and asymmetries of the long bones of the limbs and clavicles in man and apes. Human Biology 9: 281-328.

Schultz AH (1949). Sex differences in the pelves of primates. American Journal of Physical Anthropology 7(3): 401-424.

Schultz AH (1963). The relative lengths of the foot skeleton and its main parts in primates. Symposia of the Zoological Society of London 1: 199-206.

Seifert L, Komar J, Araujo D, Davids K (2016). Neurobiological degeneracy: a key property for functional adaptations of perception and action to constraints. Neurosciences and Biobehavioural Reviews 69: 159-165.
Sellers WI, Cain G, Wang WJ, Crompton RH (2005). Stride lengths, speed and energy costs in walking of Australopithecus afarensis: using evolutionary robotics to predict locomotion of early human ancestors. Journal of the Royal Society Interface 2: 431-442.

Sellers WI, Pataky TC, Caravaggi P, Crompton RH (2010). Evolutionary robotic approaches in primate gait analysis. International Journal of Primatology 31: 321-338.

Senut B (1980). New data on the humerus and its joints in Plio-Pleistocene hominids. Colloqiua en Anthropologie 4: 87.

Senut B (1981). L'humérus et ses articulations chez les Hominidés plio-pléistocènes. Cahiers de Paléontologie (Paléoanthropologie), publiés sous la direction d'Y. Coppens, CNRS, Paris, $141 \mathrm{p}$.

Senut B (1982). Réflections sur la brachiation et l'origine des hominidès à la lumière des hominoïdes miocènes et des hominidés pléistocènes. Geobios 6: 335-344.

Senut B (2006). Arboreal origins of bipedalism. In Human Origins and Environmental Backgrounds (Ishida $\mathrm{H}$, Tuttle RH, Pickford $\mathrm{M}$, Ogihara N, Nakatsukasa M, eds.), pp 199208. Heidelberg, Springer.

Simpson SW, Quade J, Levin NE, Butler R, Dupont-Nivet G, Everett M, et al (2008). A female Homo erectus pelvis from Gona, Ethiopia. Science 322: 1089-1092.

Smith GE (1927). The Evolution of Man. Oxford, Oxford University Press.

Smith RJ, Jungers WL (1997). Body mass in comparative primatology. Journal of Human Evolution 32: 523-559.

Stern JT, Susman RL (1983). The locomotor anatomy of Australopithecus afarensis. American Journal of Physical Anthropology 60: 279-317.

Stratford D, Crompton RH (2021). Introduction to special issue: a $3.67 \mathrm{Ma}$ Australopithecus prometheus skeleton from Sterkfontein Caves, South Africa. Journal of Human Evolution DOI: 10.1016/j.jhevol.2021.103008.

Su DF (2016). The taphonomy and paleoecology of Korsi Dora Vertebrate Locality 1, WoransoMille Study Area, Ethiopia. In The Postcranial Anatomy of Australopithecus afarensis: New Insights from KSD-VP-1/1 (Haile-Selassie $\mathrm{Y}$, Su DF, eds.), pp 25-37. Dordrecht, Springer.

Su DF, Harrison T (2007). The palaeoecology of the Upper Laetolil Beds at Laetoli. In: Hominin Environments in the East African Pliocene: An Assessment of the Faunal Evidence (eds. Bobe R, Alemseged Z, Behrensmeyer AK) pp. 279-313. Dordrecht, Springer.

Su DF, Carlson K (2017). Comparative analysis of trabecular bone structure and orientation in South African hominin tali. Journal of $\mathrm{Hu}$ man Evolution 106: 1-18.

Susman RL, Stern JT, Jungers WL (1984). Arboreality and bipedality in the Hadar hominids. Folia Primatologica 43: 283-306.

Thorpe SK, Holder RL, Crompton RH (2007). Origin of human bipedalism as an adaptation for locomotion on flexible branches. Science 316: 1328-1331. 
Toussaint M, Macho GA, Tobias PV, Partridge TC, Hughes AR (2003). The third partial skeleton of a late Pliocene hominin (StW 431) from Sterkfontein, South Africa. South African Journal of Science 99: 215-223.

Tsegai ZJ, Skinner MM, Pahr DH, Hublin JJ, Kivell TL (2018). Systemic patterns of trabecular bone across the human and chimpanzee skeleton. Journal of Anatomy 232: 641-656.

Ungar PS, Scott RS, Grine FE, Teaford MF (2010). Molar microwear textures and the diets of Australopithecus anamensis and Australopithecus afarensis. Philosophical Transactions of the Royal Society B: Biological Sciences 365(1556): 3345-3354.

Venkataraman V, Kraft T, DeSilva J, Dominy N (2013). Phenotypic plasticity of climbing-related traits in the ankle joint of great apes and rainforest hunter-gatherers. Human Biology 85: 309-328.

Villmoare B, Kuykendall K, Rae TC, Brimacombe CS (2013). Continuous dental eruption identifies Sts 5 as the developmentally oldest fossil hominin and informs the taxonomy of Australopithecus africanus. Journal of Human Evolution 65: 798-805.

Wainwright P (1991). Ecomorphology: experimental functional anatomy for ecological problems. American Zoologist 31: 680-693.

Walker A, Leakey R (eds.) (1993). The Nariokotome Homo erectus Skeleton. Cambridge, Harvard University Press.

Wang W, Abboud RJ, Gunther MM, Crompton RH (2014). Analysis of joint force and torque for the human and non-human ape foot during bipedal walking with implications for the evolution of the foot. Journal of Anatomy 225(2): 152-166.
Wang WJ, Crompton RH (2003). Size and power required for motion with implications for the evolution of early hominids. Journal of Biomechanics 36: 1237-1246.

Wang WJ, Crompton RH (2004a). The role of load-carrying in the evolution of modern body proportions. Journal of Anatomy 204: 417-430.

Wang WJ, Crompton RH (2004b). Analysis of the human and ape foot during bipedal standing with the implications for the evolution of the foot. Journal of Biomechanics 37: 1831-1836.

Ward CV (2002). Interpreting the posture and locomotion of Australopithecus afarensis: where do we stand? Yearbook of Physical Anthropology 35: 185-215.

Ward CV (2013). Postural and locomotor adaptations of Australopithecus species. In The Paleobiology of Australopithecus (Reed KE, Fleagle JG, Leakey RE, eds.), pp 235-245. Dordrecht, Springer.

Ward CV, Leakey MG, Walker A (2001). Morphology of Australopithecus anamensis from Kanapoi and Allia Bay, Kenya. Journal of Human Evolution 41: 255-368.

Washburn SL (1967). Behavior and the origin of man. Proceedings of the Royal Anthropological Institute of Great Britain and Ireland 3: 21-27.

Watson J, Payne R, Chamberlain A, Jones R, Sellers WI (2009). The kinematics of load carrying in humans and great apes: implications for the evolution of human bipedalism. Folia Primatologica 80: 309-328.

Westcott D (2006). Effect of mobility on femur midshaft shape and robusticity. American Journal of Physical Anthropology 130: 201213.

Whitaker J, Bender A (2010). Neurobiological degeneracy: a key property for functional adaptations of perception and action to constraints. Journal of Theoretical Biology 263: 143-153.
White TD, Asfaw B, Beyene Y, Haile-Selassie Y, Lovejoy CO, Suwa G, WoldeGabriel G (2009). Ardipithecus ramidus and the paleobiology of early hominids. Science 326: 64-86.

White TD, Lovejoy CO, Asfaw B, Carlson JP, Suwa G (2015). Neither chimpanzee nor human, Ardipithecus reveals the surprising ancestry of both. Proceedings of the National Academy of Sciences of the USA 112: 48774884.

Will M, Pablos A, Stock JT (2017). Long-term patterns of body mass and stature evolution within the hominin lineage. Royal Society Open Science 4: 171339.

Williams SA, Prang TC, Meyer MR, Russo G, Shapiro LJ (2019). Re-evaluating bipedalism in Danuvius. Matters arising from M. Böhme et al. Nature https://doi.org/10.1038/s41586019-1731-0 E1-E3.

Wood B, Grabowski M (2015). Macroevolution in and around the Hominin clade. In Macroevolution (Serrelli E, Gontier N, eds.), pp 345376. Cham, Springer.

Wood B, Boyle E (2016). Hominin taxic diversity: fact or fantasy? American Journal of Physical Anthropology 159: 37-78.

Zhang Q, Chen W, Liu H-J, Li Z-Y, Song Z-H, Pan J-S, Zhang Y-Z (2009). The role of the calcar femorale in stress distribution in the proximal femur. Orthopaedic Surgery 1(4): 311-316.

Zipfel B, Berger LR (2009). Partial hominin tibia (StW 396) from Sterkfontein, South Africa. Paleontologica Africana 44: 71-75.

Zipfel B, Wunderlich R (2020). Metatarsals and pedal phalanges. In Hominin Postcranial Remains from Sterkfontein, South Africa, 19361995 (ZipfeI B, Richmond BR, Ward CV, eds.), pp 289-305. Oxford, Oxford University Press. 